NBER WORKING PAPER SERIES

\title{
STABILIZING EXPECTATIONS UNDER MONETARY AND FISCAL POLICY COORDINATION
}

\author{
Stefano Eusepi \\ Bruce Preston \\ Working Paper 14391 \\ http://www.nber.org/papers/w14391 \\ NATIONAL BUREAU OF ECONOMIC RESEARCH \\ 1050 Massachusetts Avenue \\ Cambridge, MA 02138 \\ October 2008
}

The authors thank seminar participants at the Bank of Japan, IGIER Universita Bocconi, the CAMA and Lowey Institute conference on "Fiscal Policy Frameworks", Columbia University, CREI-Universitat Pompeu Fabra, the European Central Bank conference on "Learning, Asset Prices and Monetary Policy", Federal Reserve Bank of New York, Federal Reserve Bank of St Louis "Learning Week", Indiana University, NCER Working Group in Macroeconometics, Riksbank conference on "Refining Monetary Policy: Transparency and Real Stability" and Yale University. Jordi Gali, Mike Woodford and particularly Eric Leeper and our discussants Timothy Kam, Donald Kohn and Frank Smets are thanked for useful conversations and detailed comments. The usual caveat applies. The views expressed in the paper are those of the authors and are not necessarily reflective of views at the Federal Reserve Bank of New York, the Federal Reserve System, or the Natonal Bureau of Economic Research. Preston thanks the Federal Reserve Bank of New York for its hospitality and resources while completing some of this work.

NBER working papers are circulated for discussion and comment purposes. They have not been peerreviewed or been subject to the review by the NBER Board of Directors that accompanies official NBER publications.

(C) 2008 by Stefano Eusepi and Bruce Preston. All rights reserved. Short sections of text, not to exceed two paragraphs, may be quoted without explicit permission provided that full credit, including $\odot$ notice, is given to the source. 
Stabilizing Expectations under Monetary and Fiscal Policy Coordination

Stefano Eusepi and Bruce Preston

NBER Working Paper No. 14391

October 2008

JEL No. E52,E62

\begin{abstract}
$\underline{\text { ABSTRACT }}$
This paper analyzes the constraints imposed on monetary and fiscal policy design by expectations formation. Households and firms learn about the policy regime using historical data. Regime uncertainty substantially narrows, relative to a rational expectations analysis of the model, the menu of policies consistent with expectations stabilization. There is greater need for policy coordination: the specific choice of monetary policy limits the set of fiscal policies consistent with macroeconomic stability --- and simple Taylor-type rules frequently lead to expectations-driven instability. In contrast, non-Ricardian fiscal policies combined with an interest rate peg promote stability. Resolving uncertainty about the prevailing monetary policy regime improves stabilization policy, enlarging the menu of policy options consistent with stability. However, there are limits to the benefits of communicating the monetary policy regime: the more heavily indebted the economy, the greater is the likelihood of expectations-driven instability. More generally, regardless of agents' knowledge of the policy regime, even when expectations are anchored in the long term, short-term dynamics display greater volatility than under rational expectations.
\end{abstract}

\author{
Stefano Eusepi \\ Macroeconomic and Monetary Studies Function \\ Federal Reserve Bank of New York \\ 33 Libery street \\ New York, NY 10045-0001 \\ stefano.eusepi@ny.frb.org \\ Bruce Preston \\ Department of Economics \\ Columbia University \\ 420 West 118th Street \\ New York, NY 10027 \\ and NBER \\ bp2121@columbia.edu
}




\section{Introduction}

Following Taylor (1993) a large literature has developed arguing that a simple linear relationship between nominal interest rates, inflation and some measure of real activity, can account for the behavior of the Federal Reserve and central banks in a number of developed countries. Subsequent theoretical and applied work on monetary policy has introduced such rules as behavioral equations for policymakers in general equilibrium models. Simple rules have the desirable property of stabilizing expectations when policy is sufficiently active in response to developments in the macroeconomy. This property is often referred to as the Taylor principle. It assumes that fiscal policy is Ricardian or 'passive', implying that inflation and real activity are independent of fiscal variables, and that agents have complete knowledge of the economic environment; in particular, the monetary and fiscal regime. ${ }^{1}$

The appropriateness of this view rests on policy being of a particular kind and on the absence of regime change. Yet there are clearly historical episodes indicating on-going shifts in the configuration of monetary and fiscal policy in the U.S. post-war era. They suggest that policy might better be described by evolving combinations of active and passive policy rules, for which monetary policy may or may not satisfy the Taylor principle, and fiscal policy may or may not be Ricardian. ${ }^{2}$ It is then reasonable to assume that in the initial phase of a policy regime market participants lack full information about policy or its effects on the macroeconomy. This paper evaluates the consequences of imperfect information about the prevailing policy regime, specified by simple rules, for the efficacy of stabilization policy.

We consider a model of near-rational expectations where market participants and policymakers have incomplete knowledge about the structure of the economy. Private agents are optimizing, have a completely specified belief system, but do not know the equilibrium mapping between observed variables and market clearing prices. By extrapolating from historical patterns in observed data they approximate this mapping to forecast exogenous variables relevant to their decision problems, such as prices and policy variables. Unless the monetary

\footnotetext{
${ }^{1}$ The term 'passive' follows the language of Leeper (1991). The descriptor 'Ricardian' follows Woodford (1996): for all sequences of prices, the fiscal accounts of the government are intertemporally solvent.

${ }^{2}$ The bond price support regime in the U.S. in the late 1940s discussed by Woodford (2001), and recent empirical evidence of shifting policy rules by Davig and Leeper (2006), are two examples.
} 
and fiscal authority credibly announces the policy regime in place, agents are assumed to lack knowledge of the policy rules. Because agents must learn from historical data, beliefs need not be consistent with the objective probabilities implied by the economic model. Hence, expectations need not be consistent with implemented policy — in contrast to a rational expectations analysis of the model. ${ }^{3}$

A policy regime is characterized by a monetary policy rule that specifies nominal interest rates as a function of expected inflation and a tax rule that describes how the structural surplus is adjusted in response to outstanding public debt. The central bank has imperfect knowledge about the current state: it has to forecast the current inflation rate to implement policy. The central bank therefore reacts with a delay to changing economic conditions: argued to be characteristic of actual policy-making — see McCallum (1999). Stabilization policy is harder because it is more difficult to predict business cycle fluctuations.

Policy regime changes are not explicitly modelled. Instead, a stationary model environment is studied: policy rules are constant for all time. In contrast with rational expectations, we assume that initial expectations are not consistent with the policy regime in place. The environment constitutes a best-case scenario. If agents are unable to learn the policy reaction functions describing monetary and fiscal policy in a stationary environment, then learning such objects when there are changes in policy regime can only occur under more stringent conditions.

The analysis commences by identifying a class of policies that ensures determinacy of rational expectations equilibrium in our model. Within this class, policy rules are considered desirable if they have the additional property of stabilizing expectations under imperfect information, in the sense that expectations converge to the rational expectations equilibrium associated with a given policy regime. This is adjudged by the property of expectational stability developed by Marcet and Sargent (1989) and Evans and Honkapohja (2001). Hence, good policy should be robust to both central bank and private agents' imperfect knowledge.

\footnotetext{
${ }^{3} \mathrm{~A}$ further implication of imperfect knowledge is agents respond with a delay to changes in policy. Indeed, given a change in policy regime, agents have few initial data points to infer the nature of the new regime and its implications for equilibrium outcomes. This accords with Friedman (1968), which emphasizes the existence of lags in monetary policy.
} 
This robustness property is assessed in two scenarios: one where agents have no knowledge of the monetary policy regime and one in which it is known. The latter implies all details of the central bank's monetary policy rule are correctly understood so that agents make policy consistent forecasts. Within each scenario two regimes are considered: one with active monetary and passive fiscal policy and one with passive monetary and active fiscal policy.

The central finding of the paper is that simple rules of the kind proposed by the recent literature on monetary policy design generally fail to stabilize expectations if imperfect information about the policy regime is explicitly modeled. Four specific results are of note. First, under regime uncertainty, stabilization policy is demonstrated to be more difficult than in a rational expectations analysis of the model: the menu of policies consistent with expectations stabilization is narrowed considerably. For a large class of active monetary policies that satisfy the Taylor principle, there is no choice of fiscal policy consistent with expectations stabilization. Instability arises due to a failure of traditional aggregate demand management. As real interest rates are not accurately projected, anticipated future changes in monetary policy are less effective in managing current aggregate demand.

Second, for passive monetary policies that do not satisfy the Taylor principle, there is always a choice of fiscal policy consistent with macroeconomic stability — though admissible choices depend on the precise choice of monetary policy, underscoring the need for coordination in policy design. Stability arises when uncertainty about real interest rates is small (monetary policy is sufficiently passive) and countervailing stabilizing wealth effects are strong enough (fiscal policy is sufficiently active). These wealth effects arise under this configuration of policy because beliefs tie the evolution of inflation and real activity to outstanding public debt. ${ }^{4}$ Shifts in the valuation of the latter are conducive to stability: incipient inflation pressure from excess demand reduces the value of public debt, which restrains demand and, therefore, inflation.

A corollary to these two results is period-by-period stabilization policy can be harmful. Interest rate rules that respond to estimates of current inflation and tax rules that respond to outstanding debt can lead to instability. Indeed, the stronger the dependence of policy vari-

\footnotetext{
${ }^{4}$ This is the fiscal theory of the price level. Inflation and output are no longer independent of fiscal variables.
} 
ables on endogenous macroeconomic developments, the greater the likelihood of expectationsdriven instability. This gives support to concerns about the ability of policy-makers to fine tune the macroeconomy expounded in Friedman (1968). However, a policy regime which guarantees stability of expectations comprises rules for the interest rate and structural surplus that are purely exogenous. A special class of such policies is the bond price support regime discussed by Woodford (2001).

Third, resolving uncertainty about the monetary policy regime improves the stabilization properties of simple rules. Independently of the policy regime in place, the improvement in macroeconomic stability stems from effective demand management, as the evolution of nominal interest rates becomes more predictable. However, if monetary policy is understood but market participants face uncertainty about the fiscal regime, the set of desirable stabilization policies depends on the economy's debt-to-output ratio. The more heavily indebted an economy, the smaller the menu of policies consistent with stability. That a steady state property of fiscal policy mitigates the efficacy of stabilization policy stems from a second kind of wealth effect in our model. Because households incorrectly forecast future tax changes, variations in current taxes lead to wealth effects on consumption demand: there are departures from Ricardian equivalence - compare Barro (1974). These wealth effects have magnitude proportional to the average debt-to-output ratio of the economy; are destabilizing; and engender much more persistent dynamics in response to disturbances. These findings resonate with practical policy-making, which frequently cites concern about the size of the public debt for stabilization policy.

Fourth, simple policy rules can be a source of macroeconomic instability even when expectations are anchored in the long term. In a calibrated example, we analyze the dynamic response of the economy to a small shock to inflation expectations (equivalent to a change in the perceived inflation target) under alternative assumptions about knowledge of the monetary policy regime and alternative levels of steady state government debt. Under regime uncertainty, a shock to inflation expectations leads to persistent undesired fluctuations in inflation and output before convergence to their equilibrium values. This suggests study of more sophisticated policy rules, such as targeting rules proposed by Giannoni and Woodford 
(2002), Svensson (1999) and Svensson and Woodford (2005), is warranted.

Related Literature: The analysis owes much to Leeper (1991) and the subsequent literature on the fiscal theory of the price level — see, in particular, Sims (1994), Woodford (1996) and Cochrane (1998). It also contributes to a growing literature on policy design under learning dynamics — see, inter alia, Howitt (1992), Bullard and Mitra (2002, 2006), Eusepi (2007), Evans and Honkapohja (2003, 2005, 2006), Preston (2005, 2006, 2008) - but is most directly related to Evans and Honkapohja (2007) and Eusepi and Preston (2007a). The former paper considers the interaction of monetary and fiscal policy in the context of Leeper's model under learning dynamics rather than rational expectations. The analysis here advances their findings by considering a model in which agents are optimizing conditional on their beliefs.

The latter paper analyzes the role of communication in stabilizing expectations. The presence or absence of knowledge about the policy regime is adapted from the notions of full communication and no communication developed in that paper. The results here differ in non-trivial ways as a broader class of fiscal policy is considered. Rather than assuming a zero-debt Ricardian fiscal policy, which is understood by households, the analysis here considers a class of locally Ricardian and non-Ricardian fiscal policies determined by the dual specification of a tax rule, which is unknown to agents, and choice of debt-to-output ratio. This engenders significantly richer model predictions regarding policy interactions and expectations stabilization, because agents must forecast future taxes to make current spending decisions and because holdings of the public debt are treated as net wealth.

Our analysis also connects to various papers questioning the desirability of the Taylor principle as a foundation of monetary policy design. In particular, Benhabib, Schmitt-Grohe, and Uribe (2001) show that incorporating money in household and firm decisions leads to indeterminacy in the Ricardian regime even if the Taylor principle is satisfied. Building on Edge and Rudd (2002), Leith and von Thadden (2006) show in a Leeper (1991) style model with capital that conditions for determinacy of rational expectations equilibrium depend on the debt-to-output ratio as in results presented here. Gali, Lopez-Salido, and Valles (2004) and Bilbiie (2008) develop models of limited asset market participation, and adduce evidence that the Taylor principle may be neither sufficient nor necessary for determinacy of rational 
expectations equilibrium. Our paper builds on this literature by showing that uncertainty about the mapping from primitive disturbances to equilibrium prices can similarly compromise the effectiveness of standard policy advice — despite being a minimal departure from the standard New Keynesian framework. Finally, Branch, Davig, and McGough (2008) analyze stability under learning in a model with recurrent regimes, modelled as Markov processes. Here the issue of imperfect knowledge about policy regimes is addressed in a microfounded model where regimes are non-recurrent.

The paper proceeds as follows. Section 2 lays out model microfoundations under an arbitrary assumption on expectations formation. Section 3 specifies the adopted belief structure. Section 4 revisits the analysis of Leeper (1991). Section 5 gives the core results under regime uncertainty. Section 6 discusses improving stabilization policy by resolving uncertainty about monetary policy. Section 7 concludes.

\section{A Simple Model}

The following section details a model similar in spirit to Clarida, Gali, and Gertler (1999) and Woodford (2003). A continuum of households faces a canonical consumption allocation problem and decides how much to consume of available differentiated goods and how much labor to supply to firms for the production of such goods. A continuum of monopolistically competitive firms produces differentiated goods using labor as the only input and faces a price-setting problem of the kind proposed by Calvo (1983) and implemented by Yun (1996). The major difference is the incorporation of near-rational beliefs delivering an anticipated utility model as described by Kreps (1998) and Sargent (1999). The analysis follows Marcet and Sargent (1989a) and Preston (2005), solving for optimal decisions conditional on current beliefs. 


\subsection{Microfoundations}

Households: The economy is populated by a continuum of households which seeks to maximize future expected discounted utility

$$
\hat{E}_{t}^{i} \sum_{T=t}^{\infty} \beta^{T-t}\left[\ln \left(C_{T}^{i}+g\right)-h_{T}^{i}\right]
$$

where utility depends on a consumption index, $C_{T}^{i}$, the amount of labor supplied for the production of each good $j, h_{T}^{i}$, and the quantity of government expenditures $g>0 . .^{5}$ The consumption index, $C_{t}^{i}$, is the Dixit-Stiglitz constant-elasticity-of-substitution aggregator of the economy's available goods and has associated price index written, respectively, as

$$
C_{t}^{i} \equiv\left[\int_{0}^{1} c_{t}^{i}(j)^{\frac{\theta-1}{\theta}} d j\right]^{\frac{\theta}{\theta-1}} \text { and } P_{t} \equiv\left[\int_{0}^{1} p_{t}(j)^{1-\theta} d j\right]^{\frac{1}{1-\theta}}
$$

where $\theta>1$ is the elasticity of substitution between any two goods and $c_{t}^{i}(j)$ and $p_{t}(j)$ denote household $i$ 's consumption and the price of good $j$. The discount factor is assumed to satisfy $0<\beta<1$.

$\hat{E}_{t}^{i}$ denotes the beliefs at time $t$ held by each household $i$, which satisfy standard probability laws. Section 3 describes the precise form of these beliefs and the information set available to agents in forming expectations. Households and firms observe only their own objectives, constraints and realizations of aggregate variables that are exogenous to their decision problems and beyond their control. They have no knowledge of the beliefs, constraints and objectives of other agents in the economy: in consequence agents are heterogeneous in their information sets in the sense that even though their decision problems are identical, they do not know this to be true.

Asset markets are assumed to be incomplete. The only asset in non-zero net supply is government debt to be discussed below. The household's flow budget constraint is

$$
B_{t+1}^{i} \leq R_{t}\left(B_{t}^{i}+W_{t} h_{t}^{i}+P_{t} \Pi_{t}-T_{t}-P_{t} C_{t}^{i}\right)
$$

where $B_{t}^{i}$ is household $i$ 's holdings of the public debt, $R_{t}$ the gross nominal interest rate, $W_{t}$ the nominal wage and $T_{t}$ lump-sum taxes. $\Pi_{t}$ denotes profits from holding shares in an equal

\footnotetext{
${ }^{5}$ The adopted functional form facilitates analytical results.
} 
part of each firm and $P_{t}$ is the aggregate price level defined below. Period nominal income is therefore determined as

$$
P_{t} Y_{t}^{i}=W_{t} h_{t}^{i}+\int_{0}^{1} \Pi_{t}(j) d j
$$

for each household $i$. Finally, there is a No-Ponzi constraint

$$
\lim _{T \rightarrow \infty} \hat{E}_{t}^{i} R_{t, T} B_{T}^{i} \geq 0
$$

where $R_{t, T}=\prod_{s=t}^{T-1} R_{s}^{-1}$ for $T \geq 1$ and $R_{t, t}=1 .^{6}$

A log-linear approximation to the first-order conditions of the household problem provides the Euler equation

$$
\hat{C}_{t}^{i}=\hat{E}_{t}^{i} \hat{C}_{t+1}^{i}-\left(\hat{\imath}_{t}-\hat{E}_{t}^{i} \hat{\pi}_{t+1}\right)
$$

and intertemporal budget constraint

$$
s_{C} \hat{E}_{t}^{i} \sum_{T=t}^{\infty} \beta^{T-t} \hat{C}_{T}^{i}=\frac{\bar{b}}{\bar{Y}} \hat{b}_{t}^{i}+\hat{E}_{t} \sum_{T=t}^{\infty} \beta^{T-t}\left[\hat{Y}_{T}^{i}-\frac{\bar{\tau}}{\bar{Y}} \hat{\tau}_{T}+\frac{\bar{b}}{\bar{Y}}\left(\beta \hat{\imath}_{T}-\hat{\pi}_{T}\right)\right]
$$

where

$$
\begin{aligned}
& \hat{Y}_{t} \equiv \ln \left(Y_{t} / \bar{Y}\right) ; \hat{C}_{t}^{i} \equiv \ln \left(C_{t}^{i} / \bar{C}\right) ; \hat{\imath}_{t} \equiv \ln \left(R_{t} / \bar{R}\right) ; \hat{\pi}_{t}=\ln \left(P_{t} / P_{t-1}\right) \\
& \hat{\tau}_{t} \equiv \ln \left(\tau_{t} / \bar{\tau}\right) ; \tau_{t}=T_{t} / P_{t} ; \hat{b}_{t}^{i}=\ln \left(\tilde{B}_{t}^{i} / \bar{B}\right) \text { and } \tilde{B}_{t}^{i}=B_{t}^{i} / P_{t-1}
\end{aligned}
$$

and $\bar{z}$ denotes the steady state value of any variable $z_{t}$.

Solving the Euler equation recursively backwards, taking expectations at time $t$ and substituting into the intertemporal budget constraint gives

$$
\begin{aligned}
\hat{C}_{t}^{i}= & s_{C}^{-1} \delta\left(\hat{b}_{t}^{i}-\hat{\pi}_{t}\right)+ \\
& s_{C}^{-1} \hat{E}_{t}^{i} \sum_{T=t}^{\infty} \beta^{T-t}\left[(1-\beta)\left(\hat{Y}_{T}-\delta \hat{s}_{T}\right)-(1-\delta) \beta\left(\hat{\imath}_{T}-\hat{\pi}_{T+1}\right)\right]
\end{aligned}
$$

where

$$
\hat{s}_{t}=\bar{\tau} \hat{\tau}_{t} / \bar{s} ; s_{C}=\bar{C} / \bar{Y} \text { and } \delta=\bar{s} / \bar{Y}
$$

\footnotetext{
${ }^{6}$ In general, No Ponzi does not ensure satisfaction of the intertemporal budget constraint under incomplete markets. However, given the assumption of identical preferences and beliefs and aggregate shocks, a symmetric equilibrium will have the property that all households have non-negative wealth. A natural debt limit of the kind introduced by Aiyagari (1994) would never bind.
} 
are the structural surplus (defined below), the steady state consumption-to-income ratio and the steady state structural surplus-to-income ratio. ${ }^{7}$ Optimal consumption decisions depend on current wealth and on the expected future path of after-tax income and the real interest rate. ${ }^{8}$ The optimal allocation rule is analogous to permanent income theory, with differences emerging from allowing variations in the real rate of interest, which can occur due to variations in either the nominal interest rate or inflation. Note also, that as households become more patient, current consumption demand is more sensitive to expectations about future macroeconomic conditions.

The steady state structural surplus-to-income ratio, $\delta$, affects consumption decisions in three ways: i) it determines after-tax income; ii) it reduces the elasticity of consumption spending with respect to real interest rates; and iii) it indexes wealth effects on consumption spending that result from variations in the real value of government debt holdings. To interpret these effects further it is useful to consider aggregate consumption demand. Aggregating over the continuum and rearranging provides

$$
\begin{aligned}
\hat{C}_{t}= & s_{C}^{-1} \delta\left(\left(\hat{b}_{t}-\hat{\pi}_{t}\right)-\hat{E}_{t} \sum_{T=t}^{\infty} \beta^{T-t}\left[(1-\beta) \hat{s}_{T}-\beta\left(\hat{\imath}_{T}-\hat{\pi}_{T+1}\right)\right]\right) \\
& +s_{C}^{-1} \hat{E}_{t} \sum_{T=t}^{\infty} \beta^{T-t}\left[(1-\beta) \hat{Y}_{T}-\beta\left(\hat{\imath}_{T}-\hat{\pi}_{T+1}\right)\right]
\end{aligned}
$$

where

$$
\int_{0}^{1} \hat{C}_{t}^{i} d i=\hat{C}_{t} ; \quad \int_{0}^{1} \hat{b}_{t}^{i} d i=\hat{b}_{t} ; \quad \text { and } \quad \int_{0}^{1} \hat{E}_{t}^{i} d i=\hat{E}_{t}
$$

give aggregate consumption demand; total outstanding public debt; and average expectations. The second line gives the usual terms that arise from permanent income theory. The term premultiplied by $s_{C}^{-1} \delta$ in the first line is the intertemporal budget constraint of the government. In a rational expectations analysis of the model, this is an equilibrium restriction known to be

\footnotetext{
${ }^{7}$ Calculations are in a technical appendix available at: www.columbia.edu/ bp2121/fiscalapp.pdf.

${ }^{8}$ Using the fact that total household income is the sum of dividend and wage income, combined with the first-order conditions for labor supply and consumption, delivers a decision rule for consumption that depends only on forecasts of prices: that is, goods prices, nominal interest rates, wages and dividends. However, we make the simplifying assumption that households forecast total income, the sum of dividend payments and wages received.
} 
equal to zero. However, agents might face uncertainty about the current fiscal regime in place. ${ }^{9}$ And under arbitrary subjective expectations, households may incorrectly forecast future tax obligations and real interest rates, leading to holdings of the public debt being perceived as net wealth: Ricardian equivalence need not hold out of rational expectations equilibrium. The failure of Ricardian equivalence leads to wealth effects on consumption demand, and the magnitude of these effects is indexed by the structural surplus-to-output ratio, or equivalently the debt-to-output ratio as these steady state quantities are proportional. On average, the more indebted an economy the larger are the effects on demand. This is shown to be important in the design of stabilization policy.

Finally, note that if either the debt-to-output ratio is zero or the intertemporal budget constraint is for some reason known to hold by households, then consumption demand is determined by the second term only, delivering the model analyzed by Preston $(2005,2006) .{ }^{10}$ Those papers consider the case of a zero-debt fiscal policy, understood to hold in all future periods so that households need not forecast taxes. This paper extends that analysis to a considerably broader class of fiscal policies that agents must learn about — with non-trivial consequence.

Firms. There is a continuum of monopolistically competitive firms. Each differentiated consumption good is produced according to the linear production function $y_{t}(j)=A_{t} h_{t}(j)$ where $A_{t}>0$ denotes an aggregate technology shock. Each firm faces a demand curve $Y_{t}(j)=$ $\left(P_{t}(j) / P_{t}\right)^{-\theta_{t}} Y_{t}$, where $Y_{t}$ denotes aggregate output, and solves a Calvo-style price-setting problem where prices can be optimally chosen in any period with probability $0<1-\alpha<1$. A price $p$ is chosen to maximize the expected discounted value of profits

$$
\hat{E}_{t}^{j} \sum_{T=t}^{\infty} \alpha^{T-t} Q_{t, T} \Pi_{T}^{j}(p)
$$

where

$$
\Pi_{T}^{j}(p)=p^{1-\theta} P_{T}^{\theta} Y_{T}-p^{-\theta} P_{T}^{\theta} Y_{T} W_{T} / A_{T}
$$

\footnotetext{
${ }^{9}$ The tax rule is such that each household faces the same tax profile. However, agents are not aware of that: in forecasting future tax obligations they consider the possibility that their individual tax profile might have changed.

${ }^{10}$ In general, assuming knowledge of the intertemporal budget constraint is questionable as it is just one of the many equilibrium restrictions that households are attempting to learn.
} 
denotes period $T$ profits. Given the incomplete markets assumption it is assumed that firms value future profits according to the marginal rate of substitution evaluated at aggregate income $Q_{t, T}=\beta^{T-t} P_{t} Y_{T} /\left(P_{T} Y_{t}\right)$ for $T \geq t .^{11}$

Denote the optimal price $p_{t}^{*}$. Since all firms changing prices in period $t$ face identical decision problems, the aggregate price index evolves according to

$$
P_{t}=\left[\alpha P_{t-1}^{1-\theta}+(1-\alpha) p_{t}^{* 1-\theta}\right]^{\frac{1}{1-\theta}} .
$$

Log-linearizing the first-order condition for the optimal price gives

$$
\hat{p}_{t}=\hat{E}_{t}^{i} \sum_{T=t}^{\infty}(\alpha \beta)^{T-t}\left[(1-\alpha \beta) \hat{\chi}_{T}+\alpha \beta \pi_{T+1}\right]
$$

where $\hat{p}_{t}=\log \left(p_{t}^{*} / P_{t}\right)$ and $\hat{\chi}_{t} \equiv \ln \left(\chi_{t} / \bar{\chi}\right)$ is average marginal costs defined below. Each firm's current price depends on the expected future path of real marginal costs and inflation. The higher the degree of nominal rigidity, the greater the weight on future inflation in determining current prices. The average real marginal cost function is $\chi_{t}=W_{t} /\left(P_{t} A_{t}\right)=Y_{t} / A_{t}$, where the second equality comes from the household's labor supply decision. Log-linearizing provides $\hat{\chi}_{t}=\hat{Y}_{t}-a_{t}$, where $a_{t}=\ln \left(A_{t}\right)$ so that current prices depend on expected future demand, inflation and technology.

\subsection{Monetary and Fiscal Authorities}

Monetary Policy: The central bank is assumed to implement monetary policy according to a one-parameter family of interest rate rules

$$
R_{t}=\bar{R}\left(E_{t-1}^{c b} \pi_{t}\right)^{\phi_{\pi}}
$$

where $E_{t-1}^{c b} \pi_{t}$ is a measure of current inflation and $\phi_{\pi} \geq 0$. The central bank does not observe inflation in real time and, like private agents, has an incomplete model of the economy. For simplicity, it is assumed the central bank has the same forecasting model for inflation as private agents. This is easily generalized. The nominal interest rate rule satisfies the approximation

$$
\hat{\imath}_{t}=\phi_{\pi} E_{t-1}^{c b} \hat{\pi}_{t}
$$

\footnotetext{
${ }^{11}$ The precise details of this assumption are not important to the ensuing analysis so long as in the log linear approximation future profits are discounted at the rate $\beta^{T-t}$.
} 
This class of rule has had considerable popularity in the recent literature on monetary policy. It ensures determinacy of rational expectations equilibrium if the Taylor principle is satisfied under certain assumptions about fiscal policy and exhibits other robustness properties noted by Batini and Haldane (1999) and Levin, Wieland, and Williams (2003). This has led to advocacy of forecast-based instrument rules for the implementation of monetary policy. Indeed, such policy rules appear in a number of central bank forecasting models. Furthermore, Clarida, Gali and Gertler (1998, 2000) adduce empirical evidence for a related class of interest rate reaction functions in which the central bank responds to forecasts of next-period inflation. Similar results hold for such rules.

The study of optimal policy is not pursued on two grounds. If appropriately chosen, simple rules deliver much of the welfare gains inherent in more complex optimal policy rules - see Schmitt-Grohe and Uribe (2005). Second, optimal policy in the context of learning dynamics is not trivial. Assumptions have to be made about the precise information a central bank has about the structure of the economy. While households and firms need only know their own objectives and constraints to make decisions, for a central bank to design optimal policy requires accurate information on all agents in the economy, including beliefs. However, Preston (2006) shows that appropriate choice of stochastic intercept in (6) can implement optimal policy, implying all subsequent stability results would continue to apply.

Fiscal Policy: The fiscal authority finances government purchases of $g$ per period by issuing public debt and levying lump-sum taxes. Denoting $B_{t}$ as the outstanding government debt at the beginning of any period $t$, and assuming for simplicity that the public debt is comprised entirely of one-period riskless nominal Treasury bills, government liabilities evolve according to

$$
B_{t+1}=\left(1+i_{t}\right)\left[B_{t}+g P_{t}-T_{t}\right]
$$

It is convenient to rewrite this constraint as

$$
b_{t+1}=\left(1+i_{t}\right)\left(b_{t} \pi_{t}^{-1}-s_{t}\right)
$$

where $s_{t}=T_{t} / P_{t}-g$ denotes the primary surplus and $b_{t}=B_{t} / P_{t-1}$ a measure of the real value of the public debt. Observe that $b_{t}$ is a predetermined variable since $W_{t}$ is determined a period 
in advance. ${ }^{12}$ The government's flow budget constraint satisfies the log-linear approximation

$$
\hat{b}_{t+1}=\beta^{-1}\left(\hat{b}_{t}-\hat{\pi}_{t}-(1-\beta) \hat{s}_{t}\right)+\hat{\imath}_{t} .
$$

The model is closed with an assumption on the path of primary surpluses $\left\{s_{t}\right\} .{ }^{13}$ Analogous to the monetary authority, it is assumed that the fiscal authority adjusts the primary surplus according to the one-parameter family of rules

$$
s_{t}=\bar{s}\left(\frac{b_{t}}{\bar{b}}\right)^{\phi_{\tau}}
$$

where $\bar{s}, \bar{b}>0$ are constants coinciding with the steady state level of the primary surplus and the public debt respectively. $\phi_{\tau} \geq 0$ is a policy parameter. The fiscal authority faces no uncertainty about outstanding liabilities as they are determined a period in advance. The tax rule satisfies the log-linear approximation

$$
\hat{s}_{t}=\phi_{\tau} \hat{b}_{t}
$$

Similar remarks on the matter of optimal policy apply here.

\subsection{Market clearing and aggregate dynamics}

General equilibrium requires goods market clearing,

$$
\int_{0}^{1} C_{t}^{i} d i+g=C_{t}+g=Y_{t} .
$$

This relation satisfies the log-linear approximation

$$
s_{C} \int_{0}^{1} \hat{C}_{t}^{i} d i=s_{C} \hat{C}_{t}=\hat{Y}_{t} .
$$

It is useful to characterize the natural rate of output - the level of output that would prevail absent nominal rigidities under rational expectations. Under these assumptions, optimal price setting implies the log-linear approximation $\hat{Y}_{t}^{n}=a_{t}$. Movements in the natural rate of output

\footnotetext{
${ }^{12}$ See Eusepi and Preston (2007b) for a more general analysis with multiple debt maturities.

${ }^{13}$ This is without loss of generality. It would be straightforward to specify separate policies for the revenues and expenditures of the government accounts without altering the substantive implications of the model.
} 
are determined by variations in aggregate technology shocks. Using this definition, aggregate dynamics of the economy can be characterized in terms of deviations from the flexible price equilibrium. Finally, asset market clearing requires

$$
\int_{0}^{1} B_{t}^{i} d i=B_{t} \text { and } \int_{0}^{1} \hat{b}_{t}^{i} d i=\hat{b}_{t}
$$

implying the sum of individual holdings of the public debt equals the supply of one-period bonds.

Aggregating household and firm decisions provides

$$
\begin{aligned}
\hat{x}_{t}= & \delta \beta^{-1}\left(\hat{b}_{t}-\hat{\pi}_{t}\right)-\beta^{-1} \delta \hat{s}_{t}+ \\
& \hat{E}_{t} \sum_{T=t}^{\infty} \beta^{T-t}\left[(1-\beta)\left(\hat{x}_{T+1}-\delta \hat{s}_{T+1}\right)-(1-\delta)\left(\hat{\imath}_{T}-\hat{\pi}_{T+1}\right)+r_{T}^{n}\right]
\end{aligned}
$$

assuming for analytical convenience, without loss of generality, $g=0$, so that $s_{C}=1$, and

$$
\hat{\pi}_{t}=\kappa \hat{x}_{t}+\hat{E}_{t} \sum_{T=t}^{\infty}(\alpha \beta)^{T-t}\left[\kappa \alpha \beta \hat{x}_{T+1}+(1-\alpha) \beta \hat{\pi}_{T+1}\right]
$$

where $\int_{0}^{1} \hat{E}_{t}^{i} d i=\hat{E}_{t}$ gives average expectations; $x_{t}=\hat{Y}_{t}-\hat{Y}_{t}^{n}$ denotes the log-deviation of output from its natural rate; $r_{t}^{n}=\hat{Y}_{t+1}^{n}-\hat{Y}_{t}^{n}$ the corresponding natural rate of interest - assumed to be an identically independently distributed process; and $\kappa=(1-\alpha)(1-\alpha \beta) \alpha^{-1}>0$.

The average expectations operator does not satisfy the law of iterated expectations due to the assumption of completely imperfect common knowledge on the part of all households and firms. Because agents do not know the beliefs, objectives and constraints of other households and firms in the economy, they cannot infer aggregate probability laws. This is the property of the irreducibility of long-horizon forecasts noted by Preston (2005).

To summarize, the model comprises the structural relations (6), (7), (8), (10) and (11). The model is closed with the specification of beliefs, described next.

\section{Learning: Belief Formation and the Policy Regime}

Beliefs. This section describes the central bank's and market participants' learning behavior and the criterion to assess convergence of beliefs. The optimal decisions of households and 
firms require forecasting the evolution of future real interest rates, income, taxes and inflation. The central bank has only to forecast the current inflation rate. For inflation and income (or output gap), agents are assumed to use a linear econometric model, relating inflation and income to the evolution of real government debt. That is

$$
\begin{aligned}
& \hat{x}_{t}=\omega_{0}^{x}+\omega_{0}^{x} \hat{b}_{t}+e_{t}^{x} \\
& \hat{\pi}_{t}=\omega_{0}^{\pi}+\omega_{0}^{\pi} \hat{b}_{t}+e_{t}^{\pi}
\end{aligned}
$$

where $e_{t}^{x}$ and $e_{t}^{\pi}$ are i.i.d. disturbances. The model contains the same variables that appear in the minimum state variable rational expectations solutions to the model that result under the various policy configurations described in the next section. ${ }^{14}$ And while the rational expectations solution does not contain a constant, it has a natural interpretation under learning of capturing uncertainty about the steady state.

Concerning the nominal interest rate, the fiscal surplus and debt dynamics, agents' forecasts depend on their knowledge about the monetary and fiscal regimes in place. Consider first the monetary policy regime. As in Eusepi and Preston (2007a), uncertainty about the monetary policy regime is captured by assuming that agents do not know the monetary policy rule (6). In this case agents use the model

$$
\hat{\imath}_{t}=\omega_{0}^{i}+\omega_{0}^{i} \hat{b}_{t}+e_{t}^{i}
$$

which is consistent with the minimum state variable rational expectations solutions under the various monetary and fiscal regimes described in the next section. If agents know the current monetary policy regime, then, given their beliefs about future inflation, they use the rule (6) to compute policy consistent forecasts of the future path of the nominal interest rate. ${ }^{15}$

Throughout the paper we assume that market participants face uncertainty about the fiscal regime. Agents need to forecast the future evolution of the fiscal surplus and the future evolution of debt (which is also needed to predict the evolution of output and inflation). Their

\footnotetext{
${ }^{14}$ For example, in a rational expectations equilibrium under a Ricardian regime: $\omega_{0}^{x}=0, \omega_{1}^{x}=0$ and $e_{t}^{x}=\phi_{0} r_{t}^{n}$.

${ }^{15}$ Eusepi and Preston (2007a) consider the intermediate case where agents know the policy rule but have to estimate the rule's coefficients and show that this does not alter the stability properties of the equilibrium.
} 
model is

$$
\hat{s}_{t}=\omega_{0}^{s}+\omega_{0}^{s} \hat{b}_{t}+e_{t}^{s}
$$

and

$$
\hat{b}_{t+1}=\omega_{0}^{b}+\omega_{0}^{b} \hat{b}_{t}+e_{t}^{b}
$$

which, again, is consistent with the different monetary and fiscal regimes described in the next section.

Beliefs updating and forecasting. Each period, as additional data become available, agents update the coefficients of their parametric model given by (12)-(16) using a recursive least-squares estimator. Letting $\omega^{\prime}=\left(\omega_{0}, \omega_{1}\right)$ be the vector of coefficients to estimate, $z_{t}=$ $\left(\hat{x}_{t}, \hat{\pi}_{t}, \hat{\imath}_{t}, \hat{s}_{t}, \hat{b}_{t+1}\right)$ and $q_{t-1}=\left(1, \hat{b}_{t}\right)$, the algorithm can be written in recursive terms as

$$
\begin{aligned}
& \hat{\omega}_{t}=\hat{\omega}_{t-1}+g_{t}^{-1} R_{t}^{-1} q_{t-1}\left(z_{t}-\hat{\omega}_{t-1}^{\prime} q_{t-1}\right)^{\prime} \\
& R_{t}=R_{t-1}+g_{t}^{-1}\left(q_{t-1} q_{t-1}^{\prime}-R_{t-1}\right)
\end{aligned}
$$

where $g_{t}$ is a decreasing sequence and where $\hat{\omega}_{t}$ denotes the current period's coefficient estimate. ${ }^{16}$ Agents update their estimates at the end of the period, after making consumption, labor supply and pricing decisions. This avoids simultaneous determination of the parameters defining agents' forecast functions and current prices and quantities. However, to compare the model under learning with the predictions under rational expectations, we assume that agents' expectations are determined simultaneously with consumption, labor supply and pricing decisions, so that agents observe all variables that are determined at time $t$, including $\hat{b}_{t+1}$. For example, the one-period-ahead forecast for $\hat{\pi}_{t}$ is

$$
\hat{E}_{t} \hat{\pi}_{t+1}=\hat{\omega}_{0, t-1}^{\pi}+\hat{\omega}_{1 t-1}^{\pi} \hat{b}_{t+1}
$$

where $\hat{\omega}_{0, t-1}^{\pi}$ and $\hat{\omega}_{1 t-1}^{\pi}$ are the previous period's estimates of belief parameters that define the period $t$ forecast function. Hence, they observe the same variables that a 'rational' agent would observe. The only difference is that they are attempting to learn the 'correct' coefficients that characterize optimal forecasts. Finally, the central bank interest rate decision is predetermined since it is based on $t-1$ information (including the estimates of belief parameters).

\footnotetext{
${ }^{16}$ That is, for example, $\omega_{0}=\left(\omega_{0}^{x}, \omega_{0}^{\pi}, \omega_{0}^{i}, \omega_{0}^{s}, \omega_{0}^{b}\right)$. It is assumed that $\sum_{t=1}^{\infty} g_{t}=\infty, \sum_{t=1}^{\infty} g_{t}^{2}<\infty-$ see Evans and Honkapohja (2001).
} 
True Data Generating Process. Using (12)-(16) to substitute for expectations in (5) and solving delivers the actual data generating process

$$
\begin{aligned}
z_{t} & =\Gamma_{1}\left(\hat{\omega}_{t-1}\right) q_{t-1}+\Gamma_{2}\left(\hat{\omega}_{t-1}\right) r_{t}^{n} \\
\hat{\omega}_{t} & =\hat{\omega}_{t-1}+g R_{t}^{-1} q_{t-1}\left(\left[\left(\Gamma_{1}\left(\hat{\omega}_{t-1}\right)-\hat{\omega}_{t-1}^{\prime}\right) q_{t-1}+\Gamma_{2}\left(\hat{\omega}_{t-1}\right) r_{t}^{n}\right]\right)^{\prime} \\
R_{t} & =R_{t-1}+g\left(q_{t-1} q_{t-1}^{\prime}-R_{t-1}\right)
\end{aligned}
$$

where $\Gamma_{1}(\hat{\omega})$ and $\Gamma_{2}(\hat{\omega})$ are nonlinear functions of the previous period's estimates of beliefs. The actual evolution of $z_{t}$ is determined by a time-varying coefficient equation in the state variables $\hat{b}_{t}$ and $r_{t}^{n}$, where the coefficients evolve according to (20) and (21). The evolution of $z_{t}$ depends on $\hat{\omega}_{t-1}$, while at the same time $\hat{\omega}_{t}$ depends on $z_{t}$. Learning induces selfreferential behavior. The dependence of $\hat{\omega}_{t}$ on $z_{t}$ is related to the fact that outside the rational expectations equilibrium $\Gamma_{1}\left(\hat{\omega}_{t-1}\right) \neq \hat{\omega}_{t-1}^{\prime}$ and similarly for $\Gamma_{2}$. This self-referential behavior emerges because each market participant ignores the effects of their learning process on prices and income, and this is the source of possible divergent behavior in agents' expectations.

Expectations Stability. The data generating process implicitly defines the mapping between agents' beliefs, $\omega$, and the actual coefficients describing observed dynamics, $\Gamma_{1}(\omega)$. A rational expectations equilibrium is a fixed point of this mapping. For such rational expectations equilibria we are interested in asking under what conditions does an economy with learning dynamics converge to each equilibrium. Using stochastic approximation methods, Marcet and Sargent (1989b) and Evans and Honkapohja (2001) show that conditions for convergence are characterized by the local stability properties of the associated ordinary differential equation

$$
\frac{d\left(\omega_{0}, \omega_{1}\right)}{d \tau}=\Gamma_{1}(\omega)-\omega
$$

where $\tau$ denotes notional time. ${ }^{17}$ The rational expectations equilibrium is said to be expectationally stable, or E-Stable, when agents use recursive least squares if and only if this differential equation is locally stable in the neighborhood of the rational expectations equilibrium. $^{18}$

\footnotetext{
${ }^{17}$ If $\Gamma_{1}(\omega)=\omega$, it follows from results in section 3 that $\Gamma_{2}(\omega)=\phi_{0}$ in the case of a Ricardian regime and $\Gamma_{2}(\omega)=\phi_{2}$ in the case of a non-Ricardian regime.

${ }^{18}$ Standard results for ordinary differential equations imply that a fixed point is locally asymptotically
} 


\section{Rational Expectations: Leeper Revisited}

In the standard account of monetary policy design, nominal interest rates are determined actively to stabilize inflation and output. Less emphasized, but no less important, is the accompanying assumption that fiscal policy is Ricardian — taxes are assumed to adjust in such a way as to ensure intertemporal solvency of the government budget. Under these assumptions, a central recommendation is that monetary policy should satisfy the Taylor principle: nominal interest rates should be adjusted more than one for one with variations in inflation. As shown by Leeper (1991), however, other configurations of policy are consistent with determinacy of rational expectations equilibrium. They involve a more active role for a fiscal policy which is non-Ricardian in nature and has monetary consequences. Here we revisit the fiscal theory of the price level and the determinacy properties of our model under rational expectations. Ricardian and non-Ricardian fiscal policies are formally defined. The following characterizes the set of unique equilibria under the rational expectations assumption. The analysis is analogous to Leeper (1991), though in the context of the model of section 2. All proofs are collected in the appendix.

Proposition 1 There exist unique bounded rational expectations equilibria of the indicated form if and only if the following conditions are satisfied: either

1. Monetary policy is active and fiscal policy is locally Ricardian such that

$$
1<\phi_{\tau}<\frac{1+\beta}{1-\beta} \text { and } \phi_{\pi}>1
$$

with inflation dynamics determined as

$$
\hat{\pi}_{t}=\phi_{0} r_{t}^{n} ; \quad \text { or }
$$

2. Monetary policy is passive and fiscal policy is locally non-Ricardian such that

$$
0 \leq \phi_{\pi}<1 \text { and } 0 \leq \phi_{\tau}<1 \text { or } \phi_{\tau}>\frac{1+\beta}{1-\beta}
$$

with inflation dynamics determined as

$$
\hat{\pi}_{t}=\phi_{1} \hat{b}_{t}+\phi_{2} r_{t}^{n}
$$

The coefficients $\left\{\phi_{0}, \phi_{1}, \phi_{2}\right\}$ are reported in the Appendix.

stable if all eigenvalues of the Jacobian matrix $D\left[\Gamma\left(\omega_{0}, \omega_{1}\right)-\left(\omega_{0}, \omega_{1}\right)\right]$ have negative real parts (where $D$ denotes the differentiation operator and the Jacobian is understood to be evaluated at the relevant rational expectations equilibrium). 
The descriptors locally Ricardian and non-Ricardian refer to the combined implications of the government's flow budget constraint and tax policy. When $1<\phi_{\tau}<(1+\beta) /(1-\beta)$ the eigenvalue of the difference equation (7) is inside the unit circle, and, for all bounded sequences $\left\{\pi_{t}, i_{t}\right\}$, real debt converges to its steady state value. Because taxes are adjusted to ensure intertemporal solvency of the government accounts for all possible paths of the price level, this configuration of fiscal policy is termed locally Ricardian, where locally refers to the use of a log-linear approximation. In the language of Leeper this is passive fiscal policy. In contrast, if either $0 \leq \phi_{\tau}<1$ or $\phi_{\tau}>(1+\beta) /(1-\beta)$, then the eigenvalue is outside the unit circle and real debt dynamics are inherently explosive. It is this property that requires a specific path of the price level to ensure solvency of the intertemporal accounts. Hence, locally non-Ricardian, or in the language of Leeper, active fiscal policy.

Whether fiscal policy is locally Ricardian or non-Ricardian has implications for macroeconomic dynamics. In the former case, inflation dynamics are independent of the public debt. In the latter case, the path of real debt has consequences for the determination of inflation dynamics. To assist interpretation of subsequent results, note that the equilibrium coefficient $\phi_{1}$ is larger, the smaller are the policy coefficients $\phi_{\pi}$ and $\phi_{\tau}$. In the limit $\phi_{\pi}, \phi_{\tau} \rightarrow 0$, the elasticity of inflation in response to variations in debt is largest. In the non-Ricardian regimes analyzed in the sequel, agents forecast inflation as a function of debt, and debt is shown to generate stabilizing wealth effects through expectations formation. These wealth effects are therefore largest when policy responds little to endogenous developments in the economy. The conditions for determinacy of rational expectations equilibrium in each regime are referred to as the Leeper conditions. ${ }^{19}$

\footnotetext{
${ }^{19}$ Two other classes of equilibria are possible. One concerns the case of Ricardian fiscal policy combined with a passive monetary policy satisfying $0<\phi_{\pi}<1$. In this case, there is indeterminacy of rational expectations equilibrium for all parameter values. It is easily demonstrated that none of these equilibria is stable under the alternative non-rational expectations assumption being considered. The second concerns the case of nonRicardian fiscal policy and monetary policy satisfying the Taylor principle. Under rational expectations it can be shown that there exist a class of unbounded equilibria that have explosive debt and inflation dynamics.
} 


\section{$5 \quad$ Monetary and Fiscal Regime Uncertainty}

Having laid out preparatory foundations, the analysis turns to the consequences of regime uncertainty for stabilization policy. One final assumption is required to facilitate analytical results: the economy is assumed to have only a small degree of nominal rigidity. Formally, the conditions for expectational stability are studied in the neighborhood of the limit, $\alpha \rightarrow 0$. This is not equivalent to analyzing a flexible price economy. For an arbitrary degree of nominal friction, $0<\alpha<1$, analytical results are unavailable except in two special cases. ${ }^{20}$ Section 7 also provides some more general numerical examples.

\subsection{Constraints on Stabilization Policy}

Under regime uncertainty, the following results obtain.

Proposition 2 Stabilization policy ensures expectational stability if and only if

1. Monetary policy is active and fiscal policy is locally Ricardian such that

$$
1<\phi_{\tau}<\frac{1+\beta}{1-\beta} \text { and } \phi_{\pi}>\frac{1}{1-\beta} ; \text { or }
$$

2. Monetary policy is passive and fiscal policy is locally non-Ricardian such that $0 \leq \phi_{\pi}<1$, and either

(a)

$$
0 \leq \phi_{\tau}<\min \left(\phi_{\tau}^{*}, 1\right) \text { where } \phi_{\tau}^{*}=\frac{2}{\left[\left(1-\beta \phi_{\pi}\right)^{-1}+(1-\beta)\right]} ; \text { or }
$$

$$
\phi_{\tau}>\frac{1+\beta}{1-\beta}
$$

Regime uncertainty constrains the menu of policies consistent with expectations stabilization relative to the class of policies given by the Leeper conditions. If fiscal policy is locally Ricardian then monetary policy must be highly aggressive to prevent self-fulfilling expectations. For many monetary policies satisfying the Taylor principle there is no choice

\footnotetext{
${ }^{20}$ For a numerical treatment with locally Ricardian fiscal policy, see Eusepi and Preston (2007b), which explores related issues and the consequences of the debt maturity structure for stabilization policy.
} 
of fiscal policy that can guarantee stability. The restriction on the choice of monetary policy depends on the households' discount factor, $\beta$, since this parameter regulates the impact of revisions to expectations about future macroeconomic conditions on current spending and pricing decisions. The more patient are households the larger will be the impact on current macroeconomic conditions.

If fiscal policy is non-Ricardian there are greater incentives to coordinate monetary and fiscal policy relative to a rational expectations analysis of the model. Indeed, under rational expectations, conditional on monetary policy being passive, any choice of locally nonRicardian fiscal policy delivers a unique bounded rational expectations equilibrium. Under regime uncertainty this is no longer true. The precise choice of monetary policy constrains the set of fiscal policies consistent with macroeconomic stability. However, for a given choice of monetary policy there always exists a choice of fiscal policy that prevents expectations-driven instability. Part 2(b) of the proposition shows that a fiscal policy, characterized by either an exogenous surplus or an extremely aggressive fiscal rule, is conducive to macroeconomic stability for all parameter configurations. ${ }^{21}$ Thus, perhaps surprisingly, non-Ricardian regimes appear to be more robust to learning dynamics.

Worth emphasizing is that the learning behavior of both private agents and the central bank engenders the instability result. If the central bank could perfectly observe current inflation, then the stability conditions under learning are the Leeper conditions: the same restrictions implied by local determinacy. ${ }^{22}$ The analysis thus shows that the addition of realistic assumptions about the information set of the central bank has important implications for the performance of simple rules that would not emerge under rational expectations.

Under uncertainty about both the fiscal and monetary regime, stability is independent of average indebtedness. Determinacy of rational expectations equilibrium is similarly independent of this object. The sequel demonstrates that under non-rational expectations this is not generally true. If uncertainty about the monetary policy regime is resolved, the efficacy of stabilization policy can hinge on the indebtedness of the economy and, therefore, uncertainty

\footnotetext{
${ }^{21}$ In fact, it can be shown that with an interest peg and an exogenous surplus, E-stability holds for an arbitrary degee of nominal rigidities. A proof is available in a technical appendix.

${ }^{22} \mathrm{~A}$ proof is available in a technical appendix.
} 
about the intertemporal solvency of the government accounts. This discussion is summarized in the following corollary.

Corollary 3 Under regime uncertainty, macroeconomic stabilization policy is independent of the average indebtedness of the economy.

What are the sources of instability and stability under learning dynamics? The next section considers a simple example to provide intuition for the robustness of the non-Ricardian regime. The general case is then discussed.

\subsection{Learning to Believe in the Fiscal Theory: An Example}

To illustrate the stability properties of the non-Ricardian equilibrium under learning, consider

a deterministic economy with fully flexible prices; fiscal policy characterized by zero steady state debt, $\delta=0$, and an exogenous constant surplus, $\phi_{\tau}=0$; and a central bank with perfect information about inflation so that $i_{t}=\phi_{\pi} \pi_{t}$. Under these assumptions, aggregate supply equals the natural rate of output, and the model is given by the aggregate demand and debt equations

$$
\begin{aligned}
\phi_{\pi} \hat{\pi}_{t} & =\left(1-\beta \phi_{\pi}\right) \hat{E}_{t} \sum_{T=t}^{\infty} \beta^{T-t} \hat{\pi}_{T+1} \\
\hat{b}_{t+1} & =\beta^{-1}\left(\hat{b}_{t}-\hat{\pi}_{t}\right) .
\end{aligned}
$$

Let beliefs be specified by the regressions $\hat{\pi}_{t}=\omega_{\pi} \hat{b}_{t}+\varepsilon_{\pi, t}$ and $\hat{b}_{t+1}=\omega_{b} \hat{b}_{t}+\varepsilon_{b, t}$. For simplicity assume that the intercept is not estimated. The belief structure implies

$$
\begin{aligned}
\hat{E}_{t} \sum_{T=t}^{\infty} \beta^{T-t} \hat{\pi}_{T+1} & =\omega_{\pi} \frac{\omega_{b}}{1-\beta \omega_{b}} \hat{b}_{t+1} \\
& =\omega_{\pi} \frac{\omega_{b}}{1-\beta \omega_{b}}\left[\beta^{-1} \hat{b}_{t}-\left(\beta^{-1}-\phi_{\pi}\right) \hat{\pi}_{t}\right]
\end{aligned}
$$

where the second equality uses the definition of the flow budget constraint. Inserting (25) in (23) and rearranging provides

$$
\begin{aligned}
\hat{\pi}_{t} & =\left[\phi_{\pi} \frac{1-\beta \omega_{b}}{\omega_{\pi} \omega_{b}}+\left(1-\beta \phi_{\pi}\right)\left(\beta^{-1}-\phi_{\pi}\right)\right]^{-1}\left(1-\beta \phi_{\pi}\right) \beta^{-1} \hat{b}_{t} \\
& =T\left(\omega_{\pi}, \omega_{b}\right) \hat{b}_{t}
\end{aligned}
$$


which denotes the actual evolution of inflation as a function of real debt and agents' beliefs.

In the special case $\phi_{\pi}=0$, where monetary policy is a nominal interest rate peg, the expression simplifies to

$$
\hat{\pi}_{t}=\hat{b}_{t}
$$

and observed dynamics are independent of agents' beliefs. Indeed, relation (26) corresponds to the restriction between inflation and debt that obtains in a rational expectations equilibrium under the maintained assumptions. Given $T\left(\omega_{\pi}, \omega_{b}\right)=1$, the associated ordinary differential equations characterizing learning dynamics are

$$
\dot{\omega}_{\pi}=1-\omega_{\pi} \text { and } \dot{\omega}_{b}=-\omega_{b},
$$

implying stability for all parameter values.

More generally, stability under learning depends on the relation between inflation and government debt. Suppose agents' inflation expectations increase for unmodelled reasons - formally $\omega_{\pi}>1$. The increase in inflation expectations leads to an increase in current inflation, with the increase being larger the smaller is $\phi_{\pi}$. Simultaneously, higher inflation decreases the real value of next-period holdings of the public debt, which in turn lowers expectations. In the limiting case, $\phi_{\pi} \rightarrow 0$, inflation remains unchanged - the two effects on inflation are equal and opposite. In the more general case, with $0<\phi_{\pi}<1$, the initial rise in inflation expectations is not validated by subsequent inflation data and the agents' estimate of $\omega_{\pi}$ converges back to its rational expectations equilibrium value. As long as agents' beliefs permit a possible relation between inflation and real debt, as assumed in this paper, their learning process converges to rational expectations equilibrium.

\subsection{Aggregate Demand Management and Instability}

Now consider the general case. The mechanism generating instability is the same in both Ricardian and non-Ricardian regimes and depends fundamentally on monetary policy. Consider an increase in inflation expectations in the locally Ricardian regime. Aggregate demand rises immediately, as does inflation. The initial monetary policy response is weak because the nominal interest rate is set before observing current prices. As inflation increases, the central 
bank revises its expectations of current inflation and starts increasing the nominal interest rate more than proportionally, as dictated by the Taylor Principle. Because private agents do not know the policy rule their expected path for the interest rate is flatter than under full knowledge of the policy rule: as a consequence, the gradual increase in the nominal interest rate has little initial effect on inflation expectations. As inflation continues to rise, the central bank adjusts policy until inflation expectations and actual inflation start declining. Eventually interest rates are too high and the economy contracts. A process of recessions followed by expansions ensues, leading to instability. Uncertainty about both the policy rule and the delay in the monetary policy response drive instability. Failure to manage expectations through effective restraint of aggregate demand generates destabilizing dynamics. ${ }^{23}$

A similar process occurs in the non-Ricardian regime if the policy rule prescribes a sufficiently aggressive response to inflation that it dominates the stabilizing wealth effects of real debt on inflation expectations, as described in the simple example. Proposition 2 also implies that for $\beta \rightarrow 1, \phi_{\pi}<0.5$ guarantees stability independently of $\phi_{\tau}$. For higher values of $\phi_{\pi}$ stability depends on the fiscal rule. Furthermore, a fiscal rule with $\phi_{\tau}>\phi_{\tau}^{*}$ can be shown to weaken the rational expectations equilibrium relation between real debt and inflation, making inflation expectations less responsive to the level of real debt. As a result, under learning dynamics, the wealth effects operating through the intertemporal budget constraint of the government that are embedded in household and firm beliefs, are weaker, and therefore less of a stabilizing force. Section 7 further discusses this case.

\section{Resolving Uncertainty about Monetary Policy}

To isolate the role of uncertainty about the fiscal regime, we follow Eusepi and Preston (2007a), and consider the benefits of credibly communicating the monetary policy rule to firms and households. The precise details of the monetary policy rule are announced, including the policy coefficients and conditioning variables. Knowledge of this rule serves to simplify firms' and households' forecasting problems. Indeed, agents need only forecast inflation: policy

\footnotetext{
${ }^{23}$ Eusepi and Preston (2007a) discuss in detail the case of a known Ricardian regime with zero net supply of bonds.
} 
consistent forecasts of future nominal interest rates can then be determined directly from the announced policy rule. It follows that credible announcements have the property that expectations about future macroeconomic conditions are consistent with the policy strategy of the monetary authority. ${ }^{24}$

Under communication of the policy regime the aggregate demand equation becomes

$$
\begin{aligned}
\hat{x}_{t}= & \delta \beta^{-1}\left(\hat{b}_{t}-\hat{\pi}_{t}\right)-\beta^{-1} \delta \hat{s}_{t}-(1-\delta) \phi_{\pi} \hat{E}_{t-1} \hat{\pi}_{t} \\
& +\hat{E}_{t} \sum_{T=t}^{\infty} \beta^{T-t}\left[(1-\beta)\left(\hat{x}_{T+1}-\delta \hat{s}_{T+1}\right)-(1-\delta)\left(\phi_{\pi} \beta-1\right) \hat{\pi}_{T+1}+r_{T}^{n}\right]
\end{aligned}
$$

determined by direct substitution of the monetary policy rule into equation (10). The remaining model equations are unchanged with the exception of beliefs. As nominal interest rates need not be forecast, an agent's vector autoregression model is estimated on the restricted state vector $z_{t}=\left(\hat{x}_{t}, \hat{\pi}_{t}, \hat{s}_{t}, \hat{b}_{t+1}\right)$. Knowledge of the regime does not eliminate uncertainty about the statistical laws determining state variables, as future output, inflation, taxes and real debt must still be forecasted to make spending and pricing decisions.

Proposition 4 Under knowledge of the monetary policy regime, stabilization policy ensures expectational stability if the following conditions are satisfied: either

1. Monetary policy is active and fiscal policy is locally Ricardian such that

$$
1<\phi_{\tau}<\frac{1+\beta}{1-\beta} \text { and } \phi_{\pi}>\frac{1}{1-\beta \delta} ; \text { or }
$$

2. Monetary policy is passive, $0 \leq \phi_{\pi}<1$, and fiscal policy is non-Ricardian such that

$$
0 \leq \phi_{\tau}<1 \text { and } \delta<\min \left[\frac{\left(1-\beta+\beta^{2} \phi_{\pi}\right)\left(1-\phi_{\pi}\right)}{\phi_{\pi} \beta\left(1-\beta \phi_{\pi}\right)}, 1\right] \quad \text { or }
$$

$$
\phi_{\tau}>\frac{1+\beta}{1-\beta}
$$

Remark 5 The conditions in 1. and 2.(b) are also necessary conditions.

\footnotetext{
${ }^{24}$ Emphasis is given to communication about monetary policy in view of recent developments in actual central banking pratice.
} 
Regardless of the regime, guarding against expectations-driven instability for a given choice of tax rule, $\phi_{\tau}$, requires a choice of monetary policy rule that depends on two model parameters: the household's discount factor, $\beta$, and the steady state ratio of the primary surplus to output, $\delta$ (or equivalently the steady state debt-to-output ratio since $\bar{s}=(1-\beta) \bar{b}$ ). The choice of fiscal regime, reflected in the implied average debt-to-output ratio, imposes constraints on stabilization policy. Less fiscally responsible governments have access to a smaller set of monetary policies to ensure learnability of rational expectations equilibrium. In the case of locally Ricardian fiscal policies, the higher is the average debt-to-output ratio, the more aggressive must monetary policy be to protect the economy from self-fulfilling expectations.

Similarly, under locally non-Ricardian fiscal policies, the choice of monetary policy is again constrained by the average level of indebtedness of the economy. The higher are average debt levels the more passive must be the adopted monetary policy rule. Regardless of the policy regime, for $0<\delta<1$, the menu of policies consistent with stabilizing expectations is larger than when agents are uncertain about the policy regime - compare proposition 2. This discussion is summarized in the following proposition which presents two special cases of the above results.

Proposition 6 Communication unambiguously improves stabilization policy under learning dynamics. That is, for $0<\delta<1$, a larger menu of fiscal and monetary policies is consistent with expectations stabilization under knowledge of the policy regime than under regime uncertainty. When $\delta \rightarrow 1$, the regions of stability in the communication and no communication cases coincide. When $\delta=0$, the Leeper conditions are restored.

That the stability of expectations depends on a steady state quantity through $\delta$ is surprising when compared to a rational expectations analysis. Indeed, the model indicates determinacy of equilibrium conditions to be independent of this quantity. What then is the source of this dependence?

Proposition 4 makes clear that the choice of monetary policy, $\phi_{\pi}$, and the steady state structural surplus-to-output ratio, $\delta$, play a crucial role in determining stability, in both Ricardian and non-Ricardian policy regimes. The main source of instability is a second class of wealth effects — distinct to those discussed earlier — arising from violations of Ricardian equivalence: agents perceive real bonds as net wealth out of rational expectations equilibrium. 
To provide intuition, consider a regime with active monetary policy and passive fiscal policy. Again, suppose that inflation expectations increase. Agents correctly predict a steeper path of the nominal interest rate, which restrains aggregate demand, leading to lower actual inflation. In an economy with zero net debt, this would decrease expectations driving the economy back to equilibrium. But with holdings of the public debt treated as net wealth, lower inflation generates a positive wealth effect, stimulating aggregate demand and increasing inflationary pressures. The increase in real debt is higher if the monetary authority does not observe current prices because the nominal interest rate does not immediately decrease with inflation. On the one hand, active policy restrains demand as agents expect higher future real interest rates. On the other hand, larger real debt and higher expected nominal interest rates generate wealth effects with inflationary consequences. If the monetary policy rule is not sufficiently active and the stock of government debt is large the latter prevail, leading to instability.

Further insight into this result can be obtained by considering a more general form of utility function with constant consumption intertemporal elasticity of substitution, $\sigma>0$. Aggregate demand becomes

$$
\begin{aligned}
\hat{x}_{t}= & \delta \beta^{-1}\left(\hat{b}_{t}-\hat{\pi}_{t}\right)-\beta^{-1} \delta \hat{s}_{t}-(1-\delta) \phi_{\pi} \hat{E}_{t-1} \hat{\pi}_{t} \\
& +\hat{E}_{t} \sum_{T=t}^{\infty} \beta^{T-t}\left[(1-\beta)\left(\hat{x}_{T+1}-\delta \hat{s}_{T+1}\right)-(\sigma-\delta)\left(\phi_{\pi} \beta-1\right) \hat{\pi}_{T+1}+r_{T}^{n}\right]
\end{aligned}
$$

so that a lower $\sigma$ mitigates the negative output response to an expected increase in the real rate. $^{25}$

Proposition 7 Assume $\sigma>\delta$. In a Ricardian fiscal regime, under knowledge of the monetary policy regime, stabilization policy ensures expectational stability if

$$
\phi_{\pi}>\frac{1}{1-\beta \frac{\delta}{\sigma}} .
$$

A smaller intertemporal elasticity of substitution reduces the stabilizing effects of anticipated shifts in the expected path of the nominal interest rate while increasing the relative importance of destabilizing wealth effects. As $\sigma \rightarrow \delta$, the stability condition is the same

\footnotetext{
${ }^{25}$ In this case, the Phillips curve coeffcient $\kappa$ is substituted by $\tilde{\kappa}=\kappa \sigma^{-1}$.
} 
as in the case of uncertainty about the monetary policy regime. ${ }^{26}$ However, the underlying mechanism that generates instability is quite different.

A similar logic operates with passive monetary policy and active fiscal policy. Following an increase in inflation expectations, output and inflation increase, stimulated by a decline in real interest rates. As in the simple example discussed in section 5.2, the positive relation between real debt and inflation drives the economy back to equilibrium. But higher inflation can also have a destabilizing effect because it leads to a higher expected path for the nominal interest rate, increasing the real value of interest payments on outstanding government debt. This positive wealth effect increases aggregate demand and inflation. If the latter effect is sufficiently strong the combination of monetary and fiscal policy can be destabilizing. ${ }^{27}$ That is, if monetary policy is sufficiently aggressive and the steady state level of real debt is sufficiently high, then inflationary effects dominate, leading to instability.

\section{Dynamics, Regime Uncertainty and the Public Debt}

The above theoretical results focus on the asymptotic convergence properties of agents' learning dynamics. This section has two goals. First, it shows that even when policy ensures convergence to rational expectations, uncertainty about the policy regime still has important effects on model dynamics. Second, it develops intuition on how the economy responds to shifts in agents' expectations, elucidating the sources of expectations-driven instability. The main source of instability is the delayed response of the central bank and private agents to changing economic conditions. On the one hand, monetary policy affects the economy with a delay because of agents' learning process. On the other hand, monetary policy responds with a delay to developments in current inflation because of imperfect information. The interaction between these two delays generates dynamics that are significantly different from rational expectations.

To this end, we present impulse response functions to a "small" shock to inflation ex-

\footnotetext{
${ }^{26}$ Notice that the conditions for determinacy are not affected by $\sigma$.

${ }^{27}$ It can be shown that the higher $\phi_{\tau}$, the smaller the parameter set for which we have stability. In fact the larger is $\phi_{\tau}$ the weaker the relation between real debt and inflation, and the more important the wealth effects from higher nominal rates.
} 
pectations. Two experiments are considered. The first examines model dynamics under a non-Ricardian fiscal regime when there is either imperfect or perfect knowledge of monetary policy. The analysis delineates the role of real debt dynamics in stabilizing inflation expectations and clarifies the destabilizing role of monetary policy when agents have no knowledge of the regime. The second experiment explores the role of the debt-to-output ratio in model dynamics. The monetary policy regime is assumed to be known and fiscal policy is Ricardian. High debt economies are demonstrated to be prone to instability because holdings of the public debt are perceived as net wealth. In this case, the wealth effects induced by changes in the value of real debt from a shock to inflation expectations are destabilizing.

\subsection{Generating Impulse Response Functions}

The impulse response functions to a shock to inflation expectations are generated as follows. The model is simulated 5000 times assuming shocks to the natural rate, monetary policy and tax policy have standard deviations: $\sigma_{r}=1, \sigma_{i}=0.1$ and $\sigma_{\tau}=0.1 .^{28}$ In contrast to the analytical results, the simulations make more general assumptions about the degree of nominal rigidities and the elasticity of intertemporal substitution. For the chosen calibration, the rational expectations equilibrium is stable under learning. In both experiments we assume $\beta=0.99$ for a quarterly calibration. The Calvo parameter is fixed at $\alpha=0.6$, consistent with Blinder, Canetti, Lebow, and Rudd (1998) and Bils and Klenow (2004). Finally, we consider a utility function with intertemporal elasticity of substitution of consumption equal to 0.3, consistent with broad findings in the macroeconomics literature.

The impulse response functions are computed by perturbing each simulated path by an expectational shock. The difference between these perturbed paths and the original paths provides the impulse response functions. They are non-linear because of the learning dynamics and the plotted paths correspond to the median impulse response over 5000 simulations. The perturbation is done by increasing the initial beliefs about the constant in the inflation equation, $a_{\pi, 0}$, from zero (the parameter's rational expectations equilibrium value) to 0.01 . This represents an increase in inflation expectations at all forecast horizons. It can be inter-

\footnotetext{
${ }^{28}$ Shocks to the policy rules are added to prevent agents from learning the policy coefficients after few data points. However, their inclusion does not affect the stability results.
} 
preted as a small shift in the perceived inflation target, or in the long-run inflation average. All other coefficients are initially set to their rational expectations values.

A decreasing gain is employed so that $g_{t}=g_{t-1}+1$ where $g_{0}$ is chosen to be large enough to ensure that beliefs remain in the basin of attraction - recall the theoretical results are local characterizations of dynamics. Hence, with sufficient data the analytical results of the paper guarantee beliefs will converge to the rational expectations equilibrium of the model, given appropriate choice of policy. A high choice of $g_{0}$ is equivalent to having a tight prior on the initial beliefs (in our experiments we chose $g_{0}=50$ ). A consequence, relevant to interpreting the impulse response functions, is the slow convergence to rational expectations equilibrium. There is no attempt here for empirical realism. Rather we seek to draw out general lessons about the mechanisms underlying model dynamics. ${ }^{29}$

\subsection{Stabilizing Wealth Effects}

The first experiment considers a shock to inflation expectations when monetary policy is passive but responsive to expected inflation: $\phi_{\pi}=0.9$. Fiscal policy is non-Ricardian and responds weakly to changes in aggregate debt: $\phi_{\tau}=0.05$. This latter assumption emphasizes the stabilizing wealth effects coming from the revaluation of outstanding debt. The structural surplus-to-output ratio, $\delta$, is chosen to give a debt-to-output ratio of 0.5 in steady state. ${ }^{30}$

Figures 1 and 2 demonstrate that uncertainty about the monetary policy regime generates significant amplification of a shock to expectations and impairs control of the macroeconomy. If market participants have no knowledge of the monetary policy rule, inflation, output and nominal interest rates display substantial variation relative to the case where the monetary policy regime is known. Irrespective, dynamics converge to rational expectations equilibrium.

The expectation shock initially increases long-term inflation expectations. This leads to an increase in inflation and output, as future real interest rates are expected to fall. This is

\footnotetext{
${ }^{29}$ However, Eusepi and Preston (2008) demonstrate that learning dynamics represent a promising approach to fitting observed business cycles.

${ }^{30}$ As evidenced by the propositions, the precise choice of $\delta$ is not too important when there is uncertainty about the regime - the local stability properties are independent of this quantity.
} 
shown in Figure 3, where expected future real rates are defined as

$$
\rho_{t}=\hat{E}_{t} \sum_{T=t}^{\infty} \beta^{T-t}\left(\hat{\imath}_{T}-\hat{\pi}_{T+1}\right) .
$$

If there is uncertainty about the monetary policy regime, agents fail to correctly anticipate the increase in nominal interest rates, producing a much larger drop in the expected real rate than in the case when agents know the regime. Real debt falls on impact because of higher inflation. Because beliefs about inflation in a non-Ricardian equilibrium are a linear function of debt, short-term inflation expectations fall. In fact, Figure 3 shows that the short term real rate increases. ${ }^{31}$ Real debt continues to fall after the shock, even though inflation declines (the impulse response for real debt is not reported because it mimics the response of inflation). Figure 2 reveals this happens because the nominal interest rate falls more than current inflation. The lower nominal interest rate reflects the fact that the central bank is initially under predicting inflation; actual inflation declines less than expected inflation because of higher marginal costs induced by high demand. ${ }^{32}$ Over time, the persistent decrease in real debt decreases long-term inflation expectations, which induce an increase in expected real rates, decreasing aggregate demand until convergence back to equilibrium.

Finally, when the monetary policy rule is known to agents, the economy exhibits much less variability: the response to the inflation shock is actually very close to what would happen under rational expectations where the economy stays at the steady state (expectations are anchored by construction in a rational expectations equilibrium). Agents correctly predict that the nominal interest rate is going to increase with expected inflation, resulting in a much smaller decrease in the long-term real interest rate. The example underscores that even under a regime where price dynamics are not independent of fiscal variables, uncertainty about the monetary policy regime can have profound influence on the economy's response to shocks.

\footnotetext{
${ }^{31}$ This does not immediately affect long-term expectations because the initial shock to expectations affect the perceived inflation steady state, while changes in real bonds have only temporary effects on inflation.

${ }^{32}$ In particular, according to the Phillips curve, lower inflation expectations decrease actual inflation but this decrease is balanced by the high marginal cost of production.
} 


\subsection{The Role of Indebtedness: fiscal effects in a Ricardian regime}

The second experiment explores the constraints imposed on policy by the average level of indebtedness. Market participants have full knowledge about the monetary policy regime, but still face uncertainty about the fiscal regime. We then consider the dynamic response of the economy to the same inflation shock considered above, under different assumptions about the steady state level of government debt in the economy. Monetary policy is specified as $\phi_{\pi}=1.5$ and fiscal policy as $\phi_{\tau}=4$. Two levels of average indebtedness are considered: a low debt economy, which has a debt-to-output ratio of zero on average, $\delta=0$; and a high steady state debt economy with a debt-to-output ratio of $4 \bar{b} / \bar{Y}=2.3$ (in annual terms). While the latter is arguably large, it is chosen to emphasize the dynamics that operate in a high debt economy. It is also the only asset that can be held in this economy - there is no capital. The remaining model parameters are determined as before. Both the low and high debt economies satisfy the local stability conditions of proposition 4 .

Figures 4 - 6 plot the impulse responses for output, inflation and nominal interest rates. The impulse responses for the high debt economy are distinguished by smaller impact effects and greater persistence. To understand the nature of these differences it is useful to decompose aggregate demand into the following terms

$$
\begin{aligned}
\hat{x}_{t}= & \delta\left(\beta^{-1}\left(\hat{b}_{t}-\hat{\pi}_{t}\right)-\beta^{-1} \hat{s}_{t}+\hat{E}_{t} \sum_{T=t}^{\infty} \beta^{T-t}\left[\left(\hat{\imath}_{T}-\hat{\pi}_{T+1}\right)-(1-\beta) \hat{s}_{T+1}\right]\right) \\
& +\hat{E}_{t} \sum_{T=t}^{\infty} \beta^{T-t}\left[(1-\beta) \hat{x}_{T+1}-\sigma\left(\hat{\imath}_{T}-\hat{\pi}_{T+1}\right)+r_{T}^{n}\right] \\
= & \Psi_{\delta, t}+\Psi_{R, t}
\end{aligned}
$$

where

$$
\Psi_{\delta, t}=\delta\left(\beta^{-1}\left(\hat{b}_{t}-\hat{\pi}_{t}\right)-\beta^{-1} \hat{s}_{t}+\hat{E}_{t} \sum_{T=t}^{\infty} \beta^{T-t}\left[\left(\hat{\imath}_{T}-\hat{\pi}_{T+1}\right)-(1-\beta) \hat{s}_{T+1}\right]\right)
$$

and $\Psi_{R, t}$ captures remaining terms. The variable $\Psi_{R, t}$ represents the dynamics that would obtain in a zero-debt economy, or equivalently, one in which households understood the government to be intertemporally solvent. $\Psi_{\delta, t}$ captures departures from this benchmark, representing deviations from Ricardian equivalence because holdings of the public debt are treated 
as net wealth. Precisely, it is the real value of holdings of the public debt once future tax and interest obligations are accounted for. Figures 7 and 8 plot these two terms. It is immediate that $\Psi_{\delta, t}$ generates destabilizing demand effects in a high debt economy. These wealth effects are distinct from those analyzed in the previous section, which result from beliefs tying the evolution of inflation and output to real debt.

In a regime with zero steady state debt, active monetary policy increases the expected future path of real rates reducing demand, and, in turn, curbing inflation until the economy returns to rational expectations equilibrium — see Figure 9 which plots the real long rate. In an economy with high steady state debt this channel is still present. However, deviations from Ricardian equivalence drive aggregate demand in the opposite direction. The term $\Psi_{\delta, t}$ initially rises because: i) taxes are predetermined at the time of the shock and only rise over time; ii) agents anticipate higher future real interest rates, which deliver a positive income effect from holding the public debt; and iii) there is a valuation effect from the initial fall in inflation. For these reasons, the impact effects of inflation shock on output and inflation are smaller in the high debt economy.

Figure 10 shows that the value of real debt outstanding rises over time as prices fall, preventing a fast adjustment to the steady state equilibrium. The rise in real debt occurs because the central bank over predicts inflation. As a result, actual inflation is below the nominal interest rate (as a function of expected inflation). Since monetary policy is active, inflation below steady state induces negative expected real rates. This stimulates output (as the $\psi_{R, t}$ terms becomes larger than the $\psi_{\delta, t}$ term), which eventually increases above its steady state value, together with inflation. However, over time long rates and taxes adjust to reduce outstanding public debt and stabilize inflation, inducing convergence. As in the previous experiment, there is a tight link between monetary and fiscal policy. Active monetary policy might not be sufficient to stabilize expectations if market participants face uncertainty about the fiscal regime and the government faces sufficiently high long-term debt. 


\section{Conclusions}

A model is developed to explore the constraints imposed on stabilization policy by expectations formation. Specific emphasis is given to household and firm uncertainty about the prevailing policy regime adopted by the central bank and fiscal authority.

Two central results emerge. First, when agents have no knowledge about the policy regime, stabilization policy is more difficult than under a rational expectations analysis of the model. The set of policies consistent with expectations stabilization is substantially reduced. Indeed, for a class of monetary policies satisfying the Taylor principle, there is no choice of fiscal policy that prevents self-fulfilling expectations. For passive monetary policy, there is always a choice of non-Ricardian fiscal policy that ensures stability. The precise choice depends on the specific monetary policy being implemented. An implication is that under non-rational expectations, tighter coordination of monetary and fiscal policy is desirable. That non-Ricardian fiscal policies emerge to be relatively robust to expectational instability stems from two model properties: i) passive monetary policies minimize uncertainty about the future path of nominal interest rates and ii) stabilizing wealth effects that operate through the intertemporal budget constraint of the government.

Second, under full knowledge of the monetary policy regime, stabilization policy is unambiguously improved across both Ricardian and non-Ricardian regimes. That active monetary policies are no longer a source of instability is a direct consequence of households being able to accurately project the future path of real interest rates when the monetary policy strategy is known. Similarly, under non-Ricardian fiscal policies, passive monetary policy induces less uncertainty about the path of nominal interest rates, enhancing the effectiveness of stabilization policy.

Complete knowledge of monetary strategy does not ensure that all policies consistent with determinacy of rational expectations are similarly consistent with expectational stability under learning dynamics. Whether they are or not, depends on the average level of indebtedness of the economy. Because households imperfectly forecast future tax obligations, holdings of the public debt are perceived as net wealth. As a result, variations in outstanding debt lead to Keynesian expenditure effects, and these effects can be destabilizing. The magnitude of these 
wealth effects are proportional to the steady state debt-to-output ratio. The more heavily indebted the economy the more difficult it is to stabilize the macroeconomy. 


\section{References}

Aiyagari, R. (1994): "Uninsured Idiosyncratic Risk and Aggregate Saving," Quarterly Journal of Economics, 109, 659-684.

Batini, N., And A. G. Haldane (1999): "Forward-Looking Rules for Monetary Policy," in Monetary Policy Rules, ed. by J. Taylor. University of Chicago Press, Chicago.

Benhabib, J., S. Schmitt-Grohe, and M. Uribe (2001): "Monetary Policy and Multiple Equilibria," American Economic Review, 91(1), 167-186.

Bilbite, F. (2008): "Limited Asset Market Participation and (Inverted) Keynesian Logic," forthcoming, Journal of Economic Theory.

Bils, M., And P. Klenow (2004): "Some Evidence on the Importance of Sticky Prices," Journal of Political Economy, 112, 947-985.

Blinder, A. S., E. R. D. Canetti, D. E. Lebow, And J. B. Rudd (1998): Asking about prices: A new approach to understanding Price Stickiness. New York: Russell Sage Foundation.

Branch, W. A., T. Davig, and B. McGough (2008): "Adaptive Learning in RegimeSwitching Models," unpublished, University of California, Irvine.

Bullard, J., And K. Mitra (2000): "Determinacy, Learnability and Monetary Policy Inertia," Working Paper no. 2000-030A, Federal Reserve Bank of St. Louis. [Available online at http://www.stls.frb.org/docs/research/wp/2000-001.pdf].

(2002): "Learning About Monetary Policy Rules," Journal of Monetary Economics, 49(6), 1105-1129.

Calvo, G. (1983): "Staggered Prices in a Utility-Maximizing Framework," Journal of Monetary Economics, 12, 383-98.

Clarida, R., J. Gali, and M. Gertler (1998): "Monetary Policy Rules in Practice: Some International Evidence," European Economic Review, 42, 1033-1067. 
_ (1999): "The Science of Monetary Policy: A New Keynesian Perspective," Journal of Economic Literature, 37, 1661-1707.

(2000): "Monetary Policy Rules and Macroeconomic Stability: Evidence and Some Theory," Quarterly Journal of Economics, 115, 147-180.

Cochrane, J. H. (1998): "A Frictionless View of U.S. Inflation," University of Chicago mimeo.

Davig, T., And E. Leeper (2006): "Fluctuating Macro Policies and the Fiscal Theory," in NBER Macroeconomics Annual, ed. by D. Acemoglu, K. Rogoff, and M. Woodford.

Edge, R., And J. Rudd (2002): "Taxation and the Taylor Principle," Federal Reserve Board of Governors Finance and Economics Discussion Paper 2002-51.

Eusepi, S. (2007): "Learnability and Monetary Policy: A Global Perspective," Journal of Monetary Economics, Forthcoming.

Eusepi, S., And B. Preston (2007a): "Central Bank Communication and Macroeconomic Stabilization," NBER Working Paper 13259.

— (2007b): "Stabilization Policy with Near-Ricardian Households," unpublished, Columbia University.

(2008): "Expectations, Learning and Business Cycle Fluctuations," unpublished, Columbia University and Federal Reserve Bank of New York.

Evans, G. W., And S. Honkapohja (2001): Learning and Expectations in Economics. Princeton, Princeton University Press.

- (2003): "Expectations and the Stability Problem for Optimal Monetary Policies," Review of Economic Studies, 70(4), 807-824.

- (2005): "Policy Interaction, Expectations and the Liquidity Trap," Review of Economic Dynamics, 8, 303-323. 
- (2006): "Monetary Policy, Expectations and Commitment," Scandanavian Journal of Economics, 108, 15-38.

_ (2007): "Policy Interaction, Learning and the Fiscal Theory of Prices," Macroeconomic Dynamics, forthcoming.

Friedman, M. (1968): "The Role of Monetary Policy," American Economic Review, 58(1), $1-17$.

Gali, J., J. D. Lopez-Salido, and J. Valles (2004): "Rule of Thumb Consumers and the Design of Interest Rate Rules," Journal of Journal of Money, Credit and Banking, 37, $533-572$.

Giannoni, M. P., and M. Woodford (2002): "Optimal Interest-Rate Rules: I. General Theory," NBER Working Paper no. 9419.

Howitt, P. (1992): "Interest Rate Control and Nonconvergence to Rational Expectations," Journal of Political Economy, 100(4), 776-800.

Kreps, D. (1998): “Anticipated Utility and Dynamic Choice," in Frontiers of Research in Economic Theory, ed. by D. Jacobs, E. Kalai, and M. Kamien, pp. 242-274. Cambridge: Cambridge University Press.

Leeper, E. M. (1991): “Equilibria Under 'Active' and 'Passive' Monetary and Fiscal Policies," Journal of Monetary Economics, 27, 129-147.

Leith, C., And L. Von Thadden (2006): "Monetary and Fiscal Policy Interactions ina New Keynesian Model with Capital Accumulation and Non-Ricardian Consumers," ECB Working Paper No. 649.

Levin, A., V. Wieland, and J. C. Williams (2003): "Robustness of Forecast-Based Monetary Policy Rules under Model Uncertainty," American Economic Review, 93, 622645. 
Marcet, A., and T. J. Sargent (1989a): "Convergence of Least-Squares Learning in Environments with Hidden State Variables and Private Information," Journal of Political Economy, pp. 1306-1322.

(1989b): "Convergence of Least Squares Learning Mechanisms in Self-Referential Linear Stochastic Models," Journal of Economic Theory, (48), 337-368.

McCallum, B. T. (1999): "Issues in the Design of Monetary Policy Rules," in Handbook of Macroeconomics, ed. by J. Taylor, and M. Woodford. North-Holland, Amsterdam.

Preston, B. (2005): "Learning About Monetary Policy Rules when Long-Horizon Expectations Matter," International Journal of Central Banking, 1(2), 81-126.

- (2006): "Adaptive Learning, Forecast-Based Instrument Rules and Monetary Policy," Journal of Monetary Economics, 53.

— (2008): "Adaptive Learning and the Use of Forecasts in Monetary Policy," Journal of Economic Dynamics and Control, forthcoming.

Sargent, T. J. (1999): The Conquest of American Inflation. Princeton University Press.

Schmitt-Grohe, S., And M. Uribe (2005): "Optimal Fiscal and Monetary Policy in a Medium-Scale Macroeconomic Model," in NBER Macroeconomics Annual, ed. by M. Gertler, and K. Rogoff.

Sims, C. (1994): "A Simple Model for the Determination of the Price Level and the Interaction of Monetary and Fiscal Policy," Economic Theory, 4, 381-399.

Svensson, L. E. (1999): "Inflation Targeting as a Monetary Policy Rule," Journal of Monetary Economics, 43, 607-654.

Svensson, L. E., And M. Woodford (2005): "Implementing Optimal Monetary Policy Through Inflation Forecast Targeting," in The Inflation Targeting Debate, ed. by B. S. Bernanke, and M. Woodford. University of Chicago Press. 
TAylor, J. (1993): "Discretion Versus Policy Rules in Practice," Carnegie-Rochester Conference Series on Public Policy, 39, 195-214.

Woodford, M. (1996): "Control of the Public Debt: A Requirement for Price Stability," NBER Working Paper 5684.

(2001): "Fiscal Requirements of Price Stability," Journal of Money, Credit and Banking, 33, 669-728.

(2003): Interest and Prices: Foundations of a Theory of Monetary Policy. Princeton University Press.

Yun, T. (1996): "Nominal Price Rigidity, Money Supply Endogeneity, and Business Cycles," Journal of Monetary Economics, 37, 345-370.

\section{A Appendix}

\section{B Proof of Proposition 1}

The model under rational expectations is given by

$$
\begin{aligned}
& \hat{x}_{t}=E_{t} \hat{x}_{t+1}-\left(\hat{\imath}_{t}-E_{t} \hat{\pi}_{t+1}-r_{t}^{n}\right) \\
& \hat{\pi}_{t}=\kappa \hat{x}_{t}+\beta E_{t} \hat{\pi}_{t+1} .
\end{aligned}
$$

The debt dynamics and policy rules are as specified earlier. Solving the model under Ricardian fiscal policy is standard and yields $\hat{\pi}_{t}=\phi_{0} r_{t}$ where $\phi_{0}$ is a time-invariant coefficient, the specific value of which plays not role for the stability results under both learning and rational expectations. To solve the model under the assumption of non-Ricardian fiscal policy note that the governments flow budget constraint is again solved forward to give

$$
\begin{aligned}
\hat{b}_{t} & =\frac{\beta}{1-(1-\beta) \phi_{\tau}} \hat{b}_{t+1}+\frac{\left(1-\beta \phi_{\pi}\right)}{1-(1-\beta) \phi_{\tau}} \hat{\pi}_{t} \\
& =\frac{\left(1-\beta \phi_{\pi}\right)}{1-(1-\beta) \phi_{\tau}} \sum_{j=0}^{\infty}\left(\frac{\beta}{1-(1-\beta) \phi_{\tau}}\right)^{j} E_{t} \hat{\pi}_{t+j} .
\end{aligned}
$$


Since the eigenvalue pertaining to debt is great than one that implies that only one of the remaining two eigenvalues can lie in the unit circle.

Considering the sub-system in output and prices gives

$$
E_{t}\left[\begin{array}{l}
\hat{\pi}_{t+1} \\
\hat{x}_{t+1}
\end{array}\right]=\left[\begin{array}{cc}
\beta^{-1} & -\kappa \beta^{-1} \\
\left(\phi_{\pi}-\beta^{-1}\right) & 1+\kappa \beta^{-1}
\end{array}\right]\left[\begin{array}{l}
\hat{\pi}_{t} \\
\hat{x}_{t}
\end{array}\right]-\left[\begin{array}{l}
0 \\
\sigma
\end{array}\right] r_{t}^{n}
$$

with associated characteristic equation

$$
P(\lambda)=\lambda^{2}-\left(\frac{1+\beta+\kappa}{\beta}\right) \lambda+\left(\frac{1+\kappa \phi_{\pi}}{\beta}\right) .
$$

There will be one eigenvalue inside the unit circle if and only if $\phi_{\pi}<1$.

Denoting the unstable root by $\lambda_{1}$, the associated eigenvector can be determined from

$$
\left[\begin{array}{ll}
1 & d_{1}
\end{array}\right]\left[\begin{array}{cc}
\beta^{-1} & -\kappa \beta^{-1} \\
\left(\phi_{\pi}-\beta^{-1}\right) & 1+\kappa \beta^{-1}
\end{array}\right]=\left[\begin{array}{ll}
1 & d_{1}
\end{array}\right] \lambda_{1}
$$

implying that

$$
\begin{aligned}
d_{1} & =\frac{\kappa \beta^{-1}}{1+\kappa \beta^{-1}-\lambda_{1}} \\
& =\frac{\kappa}{\beta \lambda_{2}-1}
\end{aligned}
$$

where the second equality follows from noting that the roots satisfy $\lambda_{1}+\lambda_{2}=(1+\beta+\kappa) \beta^{-1}$. Transforming the system with the unstable eigenvector gives

$$
E_{t} \bar{z}_{t+1}=\lambda_{1} \bar{z}_{t}+\frac{\kappa}{1-\lambda_{2} \beta} r_{t}^{n}
$$

where

$$
\bar{z}_{t}=\left[\begin{array}{ll}
1 & d_{1}
\end{array}\right]\left[\begin{array}{l}
\hat{\pi}_{t} \\
\hat{x}_{t}
\end{array}\right]
$$

Solving forward provides

$$
\hat{\pi}_{t}=\frac{\kappa}{1-\beta \lambda_{2}} \hat{x}_{t}+\frac{\kappa}{\left(\beta \lambda_{2}-1\right) \lambda_{1}} r_{t}^{n}
$$

placing a linear restriction on output and inflation movements in equilibrium.

Substitution into the Phillips curve gives

$$
E_{t} \hat{\pi}_{t+1}=\lambda_{2} \hat{\pi}_{t}-\frac{\beta^{-1}}{\lambda_{1}} r_{t}^{n}
$$


and solving backwards recursively and taking expectations at time $t$ implies

$$
E_{t} \hat{\pi}_{t+j}=\lambda_{2}^{j} \hat{\pi}_{t}-\frac{\beta^{-1}}{\lambda_{1}} \lambda_{2}^{j-1} r_{t}^{n} .
$$

Using this to evaluate the expectations in the debt equations gives

$$
\begin{aligned}
\hat{\pi}_{t} & =\tilde{\phi}_{1}^{-1} \hat{b}_{t}+\tilde{\phi}_{1}^{-1} \tilde{\phi}_{2} r_{t} \\
& =\phi_{1} \hat{b}_{t}+\phi_{2} r_{t}
\end{aligned}
$$

where

$$
\begin{aligned}
& \tilde{\phi}_{1}=\frac{\left(1-\beta \phi_{\pi}\right)}{1-(1-\beta) \phi_{\tau}-\beta \lambda_{2}} \\
& \tilde{\phi}_{2}=\frac{\left(1-\beta \phi_{\pi}\right)}{\lambda_{1}\left(1-(1-\beta) \phi_{\tau}-\beta \lambda_{2}\right)\left(1-(1-\beta) \phi_{\tau}\right)}
\end{aligned}
$$

and

$$
\lambda_{2}=\frac{1}{2 \beta}\left[1+\beta+\kappa-\sqrt{(1+\beta+\kappa)^{2}-4 \beta\left(1+\kappa \phi_{\pi}\right)}\right] .
$$

\section{Constructing the True Data Generating Process}

This section outlines the beliefs of agents in our benchmark analysis. We re-write the model in matrix form. Each agent's estimated model at date $t$ can be expressed as

$$
X_{t}=\left[\begin{array}{lllll}
x_{t} & \pi_{t} & b_{t+1} & i_{t} & s_{t}
\end{array}\right]^{\prime}=\omega_{0, t}+\omega_{1, t} X_{t-1}+\bar{e}_{t}
$$

where $\omega_{0}$ denotes the constant, $\omega_{1}$ is defined as

$$
\omega_{1}=\left[\begin{array}{ccccc}
0 & b_{x}^{\pi} & b_{x}^{b} & 0 & 0 \\
0 & b_{\pi}^{\pi} & b_{\pi}^{b} & 0 & 0 \\
0 & b_{b}^{\pi} & b_{b}^{b} & 0 & 0 \\
0 & b_{i}^{\pi} & b_{i}^{b} & 0 & 0 \\
0 & b_{s}^{\pi} & b_{s}^{b} & 0 & 0
\end{array}\right] .
$$

and $\bar{e}_{t}$ represents an i.i.d. estimation error.

The model, given by equations $(6),(7),(8),(10)$ and (11), can be written as: 


\section{Output gap}

$$
\Psi_{x}^{1} X_{t}=\Psi_{x}^{2} \hat{E}_{t} \sum_{T=t}^{\infty} \beta^{T-t} X_{T+1}+r_{t}^{n}
$$

where

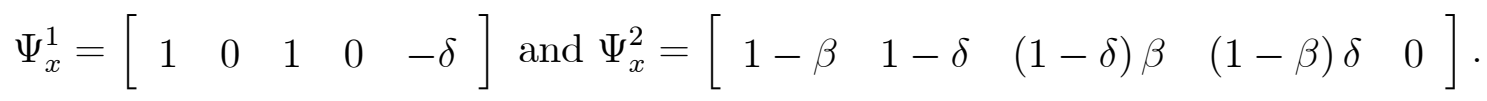

\section{Inflation}

$$
\Psi_{\pi}^{1} X_{t}=\Psi_{\pi}^{2} \hat{E}_{t} \sum_{T=t}^{\infty}(\alpha \beta)^{T-t} X_{T+1}
$$

where

$$
\Psi_{\pi}^{1}=\left[\begin{array}{lllll}
-\kappa & 1 & 0 & 0 & 0
\end{array}\right] \text { and } \Psi_{\pi}^{2}=\left[\begin{array}{lllll}
\kappa \alpha \beta & (1-\alpha) \beta & 0 & 0 & 0
\end{array}\right] .
$$

Interest rate

$$
\Psi_{i}^{1} X_{t}=\Psi_{i}^{2} \omega_{0}+\Psi_{i}^{2} \omega_{1} X_{t-1}
$$

where

$$
\Psi_{i}^{1}=\left[\begin{array}{lllll}
0 & 0 & 1 & 0 & 0
\end{array}\right] \text { and } \Psi_{i}^{2}=\left[\begin{array}{lllll}
0 & \phi_{\pi} & 0 & 0 & 0
\end{array}\right] .
$$

\section{Surplus}

$$
\Psi_{s}^{1} X_{t}=\Psi_{s}^{2} X_{t-1}
$$

where

$$
\Psi_{s}^{1}=\left[\begin{array}{lllll}
0 & 0 & 0 & 1 & 0
\end{array}\right] \text { and } \Psi_{s}^{2}=\left[\begin{array}{ccccc}
0 & 0 & 0 & 0 & \phi_{\tau}
\end{array}\right]
$$

\section{Debt}

$$
\Psi_{b}^{1} X_{t}=\Psi_{b}^{2} X_{t-1}
$$

where

$$
\Psi_{b}^{1}=\left[\begin{array}{lllll}
0 & \beta^{-1} & -1 & \beta^{-1}(1-\beta) & 1
\end{array}\right] \text { and } \Psi_{b}^{2}=\left[\begin{array}{lllll}
0 & 0 & 0 & 0 & \beta^{-1}
\end{array}\right] .
$$

Calculating expectations over an infinite horizon provides

$$
\begin{aligned}
\hat{E}_{t} \sum_{T=t}^{\infty} \beta^{T-t} X_{T+1}= & \left(I-\omega_{1}\right)^{-1}\left(I \cdot(1-\beta)^{-1}-\omega_{1}\left(I-\beta \omega_{1}\right)^{-1}\right) \omega_{0} \\
& +\omega_{1}\left(I-\beta \omega_{1}\right)^{-1} \\
= & F_{x 0}\left(\omega_{0}, \omega_{1}\right)+F_{x 1}\left(\omega_{1}\right) X_{t-1}
\end{aligned}
$$


and

$$
\begin{aligned}
\hat{E}_{t} \sum_{T=t}^{\infty}(\alpha \beta)^{T-t} X_{T+1}= & \left(I-\omega_{1}\right)^{-1}\left(I \cdot(1-\alpha \beta)^{-1}-\omega_{1}\left(I-\beta \omega_{1}\right)^{-1}\right) \omega_{0} \\
& +\omega_{1}\left(I-\alpha \beta \omega_{1} \cdot\right)^{-1} X_{t-1} \\
= & F_{\pi 0}\left(\omega_{0}, \omega_{1}\right)+F_{\pi 1}\left(\omega_{1}\right) X_{t-1} .
\end{aligned}
$$

The true data generating process is then

$$
X_{t}=\left[A_{0}\left(\omega_{1}\right)\right]^{-1}\left[A_{1}\left(\omega_{0}, \omega_{1}\right)+A_{2}\left(\omega_{1}\right)\right] X_{t-1}+\left[A_{0}\left(\omega_{1}\right)\right]^{-1} r_{t}^{n}
$$

where

$$
A_{0}\left(\omega_{1}\right)=\left[\begin{array}{l}
\Psi_{x}^{1}-\Psi_{x}^{2} F_{x 1}\left(\omega_{1}\right) \\
\Psi_{\pi}^{1}-\Psi_{\pi}^{2} F_{\pi 1}\left(\omega_{1}\right) \\
\Psi_{i}^{1} \\
\Psi_{s}^{1} \\
\Psi_{b}^{1}
\end{array}\right]
$$

and

$$
A_{1}\left(\omega_{0}, \omega_{1}\right)=\left[\begin{array}{l}
\Psi_{x}^{2} F_{x 0}\left(\omega_{0}, \omega_{1}\right) \\
\Psi_{\pi}^{2} F_{\pi 0}\left(\omega_{0}, \omega_{1}\right) \\
\Psi_{i}^{2} \omega_{0} \\
\mathbf{0} \\
\mathbf{0}
\end{array}\right] \text { and } A_{2}\left(\omega_{1}\right)=\left[\begin{array}{l}
\mathbf{0} \\
\mathbf{0} \\
\Psi_{i}^{2} \omega_{1} \\
\Psi_{s}^{2} \\
\Psi_{b}^{2}
\end{array}\right]
$$

Finally, the data generating process can be rearranged as

$$
\begin{aligned}
X_{t} & =A_{0}\left(\omega_{1}\right)^{-1} A_{1}\left(\omega_{0}, \omega_{1}\right)+A_{0}\left(\omega_{1}\right)^{-1} A_{2}\left(\omega_{1}\right) X_{t-1}+A_{0}\left(\omega_{1}\right)^{-1} r_{t}^{n} \\
& =\Gamma_{1}\left(\omega_{0}, \omega_{1}\right)\left[\begin{array}{c}
1 \\
X_{t-1}
\end{array}\right],
\end{aligned}
$$

E-stability can be computed by evaluating the local stability of the following ODE

$$
\frac{d\left(\omega_{0}, \omega_{1}\right)}{d \tau}=\Gamma_{1}\left(\omega_{0}, \omega_{1}\right)-\left(\omega_{0}, \omega_{1}\right)
$$




\section{Stability under learning}

As explained above, convergence of the learning process depends on the stability properties of the ODE (33). This is a fairly complicated convolutions of the agent's beliefs $\left(\omega_{0}, \omega_{1}\right)$. In order to find analytical conditions for convergence we make use of Matlab symbolic toolbox. The expressions can be reproduced by running the appropriate files, available on request from the authors.

\section{E Proof of Proposition 2}

Ricardian regime The results reported in this proof can be reproduced using the Matlab file: fiscal_delay_benchmark.m. First, it can be shown that the beliefs $\left(\omega_{0}, \omega_{1}\right)$ evolve according to two separate sub-systems

$$
\dot{\omega}_{0}=\left(A-I_{5}\right) \omega_{0} \text { and } \dot{\omega}_{1}=\left(B-I_{5}\right) \omega_{1} .
$$

where $A$ and $B$ represent components of the Jacobian of $\bar{T}\left(\omega_{0}, \omega_{1}\right)$, evaluated at the rational expectations equilibrium $\omega_{0}^{*}, \omega_{1}^{*}$, defined in the previous proposition.

Consider the evolution of the intercept $\omega_{0}$. We take three steps in order to reduce the matrix $A$ from a five dimensional to three dimensional object. First, evaluating the matrix $A$ reveals that

$$
\dot{\omega}_{0}^{s}=-\omega_{0}^{s}
$$

Hence, the intercept in the fiscal rule equation converges for all parameter values, independently of the other elements of the beliefs vector. This reduces dimensionality by one. Second, using the restriction

$$
A_{5, j}=-\beta^{-1} A_{2, j}+A_{3, j} \text { for } j=1 \ldots 5
$$

delivers the three dimension system (see the Matlab file for the details of the variables' transformation):

$$
\left[\begin{array}{c}
\dot{\omega}_{0}^{x} \\
\dot{\omega}_{0}^{\pi} \\
\dot{\omega}_{0}^{i}
\end{array}\right]=\tilde{A}\left[\begin{array}{c}
\omega_{0}^{x} \\
\omega_{0}^{\pi} \\
\omega_{0}^{i}
\end{array}\right] .
$$


For the real parts of the three eigenvalues to be negative requires

$$
\operatorname{Tr}(\tilde{A})<0, \operatorname{det}(\tilde{A})<0
$$

and

$$
M_{\tilde{A}}=-\operatorname{Sm}(\tilde{A}) \cdot \operatorname{Tr}(\tilde{A})+\operatorname{det}(\tilde{A})>0
$$

where $\operatorname{Sm}(\tilde{A})$ denotes the sum of all principles minors of $\tilde{A}$. We are interested in the limit case where $\alpha \rightarrow 0$. In this case, the trace, determinant and $M_{\tilde{A}}$ become arbitrarily large. Consider the trace first. We can calculate the limit

$$
\lim _{\alpha \rightarrow 0^{+}} \alpha \cdot \operatorname{Tr}(\tilde{A})=-\frac{\phi_{\pi}-1-\phi_{\pi} \beta}{1-\beta}
$$

which is negative if and only if

$$
\phi_{\pi}>\frac{1}{1-\beta}
$$

Likewise, the determinant

$$
\lim _{\alpha \rightarrow 0^{+}} \alpha \operatorname{det}(\tilde{A})=-\frac{\phi_{\pi}-1}{1-\beta}
$$

which is negative if and only if $\phi_{\pi}>1$. For $M_{\tilde{A}}$ we have

$$
\lim _{\alpha \rightarrow 0^{+}} \alpha^{2} \cdot M_{\tilde{A}}=\frac{\left(2-2 \phi_{\pi}+\phi_{\pi} \beta\right)\left(1-\phi_{\pi}+\phi_{\pi} \beta\right)}{(1-\beta)^{2}}
$$

which is positive provided (34).

Consider now the coefficients on real debt. An identical process reduces the dimensionality of the matrix $B$ to a three dimensional matrix $\tilde{B}$. Considering the trace we get

$$
\lim _{\alpha \rightarrow 0^{+}} \alpha \cdot \operatorname{Tr}(\tilde{B})=\frac{1-\phi_{\tau}(1-\beta)\left(\beta \phi_{\pi}+1\right)}{\phi_{\tau} \beta(1-\beta)}
$$

which is decreasing in $\phi_{\tau}$. In a Ricardian regime, $\phi_{\tau}>1$. Evaluating the expression at $\phi_{\tau}=1$, if (34) then the trace of the $\tilde{B}$ matrix is negative. Evaluating the determinant we get

$$
\lim _{\alpha \rightarrow 0^{+}} \alpha \cdot \operatorname{det}(\tilde{B})=\frac{1-\beta \phi_{\pi}-\beta^{-1} \phi_{\tau} \beta(1-\beta)}{\phi_{\tau} \beta(1-\beta)}
$$

which is decreasing in $\phi_{\tau}$. Again, imposing $\phi_{\tau}=1$ gives

$$
\lim _{\alpha \rightarrow 0^{+}} \alpha \cdot \operatorname{det}(\tilde{B})=-\frac{\phi_{\pi}-1}{\phi_{\tau}(1-\beta)}<0 .
$$


Finally,

$$
\lim _{\alpha \rightarrow 0^{+}} \alpha^{2} \cdot M_{\tilde{B}}=\frac{\left[\phi_{\tau}(\beta-1)\left(\beta \phi_{\pi}+2\right)-\beta \phi_{\pi}+2\right]\left[\phi_{\tau}(\beta-1)\left(\beta \phi_{\pi}+1\right)+1\right]}{\beta^{2} \phi_{\tau}^{2}(1-\beta)^{2}} .
$$

which is, again, decreasing in $\phi_{\tau}$.Imposing $\phi_{\tau}=1$ yields

$$
\lim _{\alpha \rightarrow 0^{+}} \alpha^{2} \cdot M_{\tilde{B}}=\frac{\left(2-2 \phi_{\pi}+\beta \phi_{\pi}\right)\left(1-\phi_{\pi}+\beta \phi_{\pi}\right)}{\beta \phi_{\tau}^{2}(1-\beta)^{2}}
$$

which is positive if (34) is satisfied.

Non-Ricardian regime The matrices $A$ and $B$ corresponding to the non-Ricardian regime can be reduced to three dimensional matrices by following the same steps as above. To further simplify the problem, we use two Lemmas.

Lemma 8 Consider the model where $\alpha \rightarrow 0$. Then $\lambda_{2} \rightarrow \phi_{\pi}$.

Proof. Recall that

$$
\lambda_{2}=\frac{1}{2 \beta}\left[1+\beta+\kappa(\alpha)-\sqrt{(1+\beta+\kappa(\alpha))^{2}-4 \beta\left(1+\kappa(\alpha) \phi_{\pi}\right)}\right] .
$$

We can then evaluate

$$
\begin{gathered}
\lim _{\alpha \rightarrow 0} \lambda_{2}= \\
\frac{1}{2 \beta} \lim _{\alpha \rightarrow 0} \frac{\left\{\begin{array}{c}
{\left[1+\beta+\kappa(\alpha)+\sqrt{(1+\beta+\kappa(\alpha))^{2}-4 \beta\left(1+\kappa(\alpha) \phi_{\pi}\right)}\right] \times} \\
{\left[1+\beta+\kappa(\alpha)-\sqrt{(1+\beta+\kappa(\alpha))^{2}-4 \beta\left(1+\kappa(\alpha) \phi_{\pi}\right)}\right]}
\end{array}\right\}}{\left[1+\beta+\kappa(\alpha)+\sqrt{(1+\beta+\kappa(\alpha))^{2}-4 \beta\left(1+\kappa(\alpha) \phi_{\pi}\right)}\right]}= \\
\frac{1}{2 \beta} \lim _{\alpha \rightarrow 0} \frac{4 \beta\left(1+\kappa(\alpha) \phi_{\pi}\right)}{\left[1+\beta+\kappa(\alpha)+\sqrt{(1+\beta+\kappa(\alpha))^{2}-4 \beta\left(1+\kappa(\alpha) \phi_{\pi}\right)}\right]} .
\end{gathered}
$$

Using L'Hôpital

$$
\begin{array}{r}
\frac{1}{2 \beta} \lim _{\alpha \rightarrow 0}\left[4 \beta \kappa^{\prime}(\alpha) \phi_{\pi} /\left(\kappa^{\prime}(\alpha)+\frac{(1+\beta+\kappa(\alpha)) \kappa^{\prime}(\alpha)-2 \beta \kappa^{\prime}(\alpha) \phi_{\pi}}{\sqrt{(1+\beta+\kappa(\alpha))^{2}-4 \beta\left(1+\kappa(\alpha) \phi_{\pi}\right)}}\right)\right]= \\
\frac{1}{2 \beta} \lim _{\alpha \rightarrow 0}\left[4 \beta \phi_{\pi} /\left(1+\frac{(1+\beta+\kappa(\alpha))-2 \beta \phi_{\pi}}{\sqrt{(1+\beta+\kappa(\alpha))^{2}-4 \beta\left(1+\kappa(\alpha) \phi_{\pi}\right)}}\right)\right]= \\
\frac{1}{2 \beta} \lim _{\alpha \rightarrow 0} 2 \beta \phi_{\pi}=\phi_{\pi} .
\end{array}
$$


We then conjecture that as $\alpha \rightarrow 0$, one eigenvalue of $\tilde{A}$ and $\tilde{B}$ tends to -1 . The conjecture is verified in the following Lemma.

Lemma 9 Consider the model where $\alpha \rightarrow 0$. Then one eigenvalue $\psi$ of $\tilde{A}$ and $\tilde{B}$ converges to -1 .

Proof. The characteristic equations of $\tilde{A}$ and $\tilde{B}$ are

$$
\Delta^{\tilde{A}}(\psi)=\psi^{3}-\operatorname{tr}(\tilde{A}) \psi^{2}+\operatorname{Sm}(\tilde{A}) \psi-\operatorname{det}(\tilde{A})
$$

and

$$
\Delta^{\tilde{B}}(\psi)=\psi^{3}-\operatorname{tr}(\tilde{B}) \psi^{2}+S m(\tilde{B}) \psi-\operatorname{det}(\tilde{B})
$$

It can be shown that ${ }^{33}$

$$
\lim _{\alpha \rightarrow 0} \Delta^{\tilde{A}}(-1)=-1-\operatorname{tr}(\tilde{A})-\operatorname{Sm}(\tilde{A})-\operatorname{det}(\tilde{A})=0
$$

and

$$
\lim _{\alpha \rightarrow 0} \Delta^{\tilde{B}}(-1)=-1-\operatorname{tr}(\tilde{B})-\operatorname{Sm}(\tilde{B})-\operatorname{det}(\tilde{B})=0
$$

Let us consider the local stability of the intercept coefficients. The remaining two eigenvalues of $\tilde{A}$ are negative if

$$
\operatorname{tr}(\tilde{A})+1=z_{1}+z_{2}<0 \text { and } \operatorname{det}(\tilde{A})=-z_{1} z_{2}<0
$$

The trace is

$$
\operatorname{tr}(\tilde{A})=-\left[1+\frac{1-\left[1-\beta \phi_{\pi}(1-\beta)\right] \phi_{\tau}-\beta \phi_{\pi}}{1-(1-\beta) \phi_{\tau}-\beta \phi_{\pi}}\right]
$$

(a) Consider the case of $0 \leq \phi_{\tau}<1$ : the trace can be re-arranged to deliver the following relationship between $\phi_{\tau}$ and $\phi_{\pi}$ at $\operatorname{tr}(\tilde{A})=0$,

$$
\phi_{\tau}=\frac{2}{\left[\left(1-\beta \phi_{\pi}\right)^{-1}+(1-\beta)\right]}
$$

\footnotetext{
${ }^{33}$ The limit is computed in the matlab file fiscal_delay_benchmark.m.
} 
in the text. Then, $0 \leq \phi_{\tau}<\min \left(\phi_{\tau}^{*}\left(\phi_{\pi}\right), 1\right)$, where

$$
\phi_{\tau}^{*}\left(\phi_{\pi}\right)=\frac{2}{\left[\left(1-\beta \phi_{\pi}\right)^{-1}+(1-\beta)\right]},
$$

and where we use $\partial \operatorname{tr}(A) / \partial \phi_{\tau}>0$ for $\phi_{\tau} \in[0,1)$. The determinant is

$$
-\operatorname{det}(\tilde{A})=\frac{\left(1-\phi_{\tau}\right)\left(\beta \phi_{\pi}-1\right)}{(1-\beta) \phi_{\tau}+\beta \phi_{\pi}-1}>0 .
$$

Finally, consider the $B$ matrix. Proceeding in the same way as for the $\tilde{A}$ matrix, the trace can be shown to be

$$
\operatorname{tr}(\tilde{B})=-2-\frac{(1-\beta) \beta^{2} \phi_{\pi}^{2} \phi_{\tau}}{\left(-(1-\beta) \phi_{\tau}-\beta \phi_{\pi}+1\right)\left(\beta \phi_{\pi}-1\right)} .
$$

which gives the following expression for

$$
\phi_{\tau}^{* *}\left(\phi_{\pi}\right)=\frac{2}{\left(\beta^{2} \phi_{\pi}^{2}+2\left(1-\beta \phi_{\pi}\right)\right) \frac{(1-\beta)}{\left(1-\beta \phi_{\pi}\right)^{2}}}
$$

which solves $\operatorname{tr}(\tilde{B})=0$ (also shown to have positive derivative with respect to $\phi_{\tau}$ ). It can be shown that $\phi_{\tau}^{* *}\left(\phi_{\pi}\right)>\phi_{\tau}^{*}\left(\phi_{\pi}\right) \cdot{ }^{34}$ The determinant of the $\tilde{B}$ matrix is equal to -1 for every parameter value.

(b) Straightforward algebraic manipulations of (35)-(37) show that the stability condition holds for all parameter values with $\phi_{\tau}>(1+\beta) /(1-\beta)$.

\section{F Proposition 4}

The proof follows the same steps as in Proposition 2.

Ricardian Regime. The matrices $A$ and $B$ are three dimensional, given that agents do not have to forecast the nominal interest rate and the surplus. The expressions below are calculated using the file fiscal_analytical_trsp.m. Let us consider first the matrix A. We find

$$
\lim _{\alpha \rightarrow 0^{+}} \alpha \cdot \operatorname{tr}(A)=\frac{1+(\beta \delta-1) \phi_{\pi}}{1-\beta}
$$

\footnotetext{
${ }^{34}$ It can be shown that the difference betwen the denominator of $\tau^{*}$ and the denominator in $\tau^{* *}$ is equal to

$$
\left(\beta \phi_{\pi}-1\right)^{-2}\left(1-\phi_{\pi}\right) \beta>0 \text {. }
$$
}


which gives the stability condition in the main text. Thus, for $\delta=0$, we the Taylor principle obtains. Using $\delta=(1-\beta) \frac{\bar{b}}{\bar{y}}$ we can re-write the stability condition as

$$
\phi_{\pi}\left(1-\beta(1-\beta) \frac{\bar{b}}{\bar{y}}\right)-1>0
$$

so that for high levels of debt-to-output ratio and for intermediate values of the discount factor instability is likely to arise. As $\alpha \rightarrow 0$, the determinant is

$$
\lim _{\alpha \rightarrow 0^{+}} \alpha \cdot \operatorname{det}(A)=-\frac{\phi_{\pi}-1}{1-\beta}
$$

and negative provided $\left(\phi_{\pi}-1\right)>1$. Finally,

$$
\lim _{\alpha \rightarrow 0^{+}} \alpha^{2}[-\operatorname{Sm}(A) \cdot \operatorname{Tr}(A)+\operatorname{det}(A)]=\frac{\left(\phi_{\pi}(2-\beta \delta)-2\right)\left(\phi_{\pi}(1-\beta \delta)-1\right)}{(1-\beta)^{2}},
$$

which is positive provided (38) is satisfied.

Consider now the matrix $B$. The trace is satisfies

$$
\lim _{\alpha \rightarrow 0^{+}} \alpha \cdot \operatorname{tr}(B)=\frac{\left(-1+\beta+\beta^{2} \phi_{\pi} \delta-\beta \phi_{\pi} \delta\right) \phi_{\tau}-(1-\delta) \beta \phi_{\pi}+1}{(1-\beta) \beta \phi_{\tau}}
$$

and is negative provided the trace of the matrix for the constants is negative $\left(\phi_{\tau}>1\right.$ in the Ricardian fiscal regime). As $\alpha \rightarrow 0$, the determinant is always negative, that is

$$
\lim _{\alpha \rightarrow 0^{+}} \alpha \cdot \operatorname{det}(B)=-\beta^{-1}-\frac{\left(\beta \phi_{\pi}-1\right)}{(1-\beta) \beta \phi_{\tau}}<0,
$$

if $(38)$ is satisfied.

Finally, letting $\alpha \rightarrow 0$, the sum of all principle minors becomes

$$
\begin{gathered}
\lim _{\alpha \rightarrow 0^{+}} \alpha^{2}[-\operatorname{Sm}(B) * \operatorname{Tr}(B)+\operatorname{det}(B)]= \\
\frac{\left[\left(-2 \beta-\beta^{2} \phi_{\pi} \delta+\beta \phi_{\pi} \delta+2\right) \phi_{\tau}-2-\beta \phi_{\pi} \delta+2 \beta \phi_{\pi}\right]\left[\left(1+\beta \phi_{\pi} \delta-\beta-\beta^{2} \phi_{\pi} \delta\right) \phi_{\tau}-1+\beta \phi_{\pi}-\beta \phi_{\pi} \delta\right]}{\phi_{\tau}^{2} \beta^{2}(1-\beta)^{2}}
\end{gathered}
$$

which is positive provided $\phi_{\tau}>1$ (Ricardian fiscal Regime) and (38) is satisfied.

Non-Ricardian Regime. As in proposition 2, it can be shown that one eigenvalue of both matrices $A$ and $B$ is equal to -1 . We define the trace of the constant coefficients as

$$
\lim _{\alpha \rightarrow 0^{+}} \operatorname{tr}(A)+1=\Phi^{A}\left(\phi_{\tau}, \phi_{\pi}, \delta\right)
$$


First notice that

$$
\Phi_{\delta}^{A}\left(\phi_{\tau}, \phi_{\pi}, \delta\right)=\frac{\left(1-\beta \phi_{\pi}\right) \beta^{2} \phi_{\pi}}{(1-\beta)\left(1-(1-\beta) \phi_{\tau}-\beta \phi_{\pi}\right)}>0
$$

if $0 \leq \phi_{\tau}<1$ and

$$
\Phi_{\phi_{\tau}}^{A}\left(\phi_{\tau}, \phi_{\pi}, \delta\right)=\frac{\left(1-\beta \phi_{\pi}\right)\left(\beta \phi_{\pi} \delta-\phi_{\pi}+1\right) \beta}{\left(-1+\phi_{\tau}-\phi_{\tau} \beta+\beta \phi_{\pi}\right)^{2}}>0
$$

for all admissible values of $\delta, \phi_{\pi}$, and $\phi_{\tau}$, where $\Phi_{x}^{A}$ denotes the derivative of $\Phi^{A}$ with respect to the argument $x$. Second we show that for values of $\delta<\delta^{T A}$ the trace is negative. Consider $\phi_{\tau}<1$. Using the inequality above, we can solve for $\delta^{T A}$ as

$$
\Phi^{A}\left(1, \phi_{\pi}, \delta^{T A}\right)=-\frac{\left(\beta^{2} \phi_{\pi}-\beta^{2} \phi_{\pi}^{2}+\beta^{2} \phi_{\pi}^{2} \delta^{T A}+\beta \phi_{\pi}-\beta \phi_{\pi} \delta^{T A}-\beta-\phi_{\pi}+1\right)}{(1-\beta)\left(1-\phi_{\pi}\right)}=0
$$

where

$$
\delta^{T A}=\frac{\left(\left(1-\beta+\phi_{\pi} \beta^{2}\right)\left(1-\phi_{\pi}\right)\right.}{\phi_{\pi} \beta\left(1-\beta \phi_{\pi}\right)}>0 .
$$

If $\phi_{\tau}>(1+\beta) /(1-\beta)$ then $\Phi_{\delta}^{A}\left(\phi_{\tau}, \phi_{\pi}, \delta\right)<0$. Evaluating $\Phi^{A}$ at $\delta=0$ gives

$$
\Phi^{A}\left(\phi_{\tau}, \phi_{\pi}, 0\right)=\frac{\left(C_{\phi_{\tau}} \phi_{\tau}-\beta^{3} \phi_{\pi}^{2}+3 \beta^{2} \phi_{\pi}-2 \beta \phi_{\pi}-2 \beta+2\right)}{(1-\beta)\left((1-\beta) \phi_{\tau}-1+\beta \phi_{\pi}\right)}
$$

where

$$
C_{\phi_{\tau}}=\left(\beta^{3} \phi_{\pi}-2 \beta^{2} \phi_{\pi}-\beta^{2}+\beta \phi_{\pi}+3 \beta-2\right)
$$

The denominator is positive for $\phi_{\tau}>(1+\beta) /(1-\beta)$. For the numerator, substituting $\phi_{\tau}=((1+\beta) /(1-\beta))$ gives

$$
\left(C_{\phi_{\tau}} \phi_{\tau}-\beta^{3} \phi_{\pi}^{2}+3 \beta^{2} \phi_{\pi}-2 \beta \phi_{\pi}-2 \beta+2\right)=\left(\beta^{2}-\beta\right)+\left(\beta^{2} \phi_{\pi}-\beta \phi_{\pi}\right)+\left(2 \beta^{2} \phi_{\pi}-2 \beta\right)-\beta^{3} \phi_{\pi}-\beta^{3} \phi_{\pi}^{2}<0
$$

Last, the coefficient $C_{\phi_{\tau}}$ is positive since

$$
\left(\beta^{3} \phi_{\pi}-\beta^{2} \phi_{\pi}\right)+R\left(\phi_{\pi}, \beta\right)<0
$$

where

$$
\begin{gathered}
R\left(\phi_{\pi}, \beta\right)=-\beta^{2} \phi_{\pi}-\beta^{2}+\beta \phi_{\pi}+3 \beta-2 \\
R(0, \beta)=-(\beta-1)^{2}-1+\beta<0, \quad R(1, \beta)=-2(\beta-1)^{2}<0
\end{gathered}
$$


and

$$
R_{\phi_{\pi}}\left(\phi_{\pi}, \beta\right)=-\beta^{2}+\beta>0 \text {. }
$$

Hence, for $\phi_{\tau}>(1+\beta) /(1-\beta)$ the trace is negative. Finally, the determinant of the Jacobian is

$$
\lim _{\alpha \rightarrow 0^{+}}[-\operatorname{det}(A)]=\frac{\left(1-\phi_{\tau}\right)\left(1-\beta \phi_{\pi}\right)}{1-(1-\beta) \phi_{\tau}-\beta \phi_{\pi}}>0 .
$$

Following the same steps for matrix $B$ :

$$
\lim _{\alpha \rightarrow 0^{+}} \operatorname{tr}(B)+1=\Phi^{B}\left(\phi_{\tau}, \phi_{\pi}, \delta\right)
$$

First notice that

$$
\Phi_{\delta}^{B}\left(\phi_{\tau}, \phi_{\pi}, \delta\right)=\frac{\beta^{2} \phi_{\pi}^{2}}{(1-\beta)\left(1-(1-\beta) \phi_{\tau}-\beta \phi_{\pi}\right)}>0
$$

for $0<\phi_{\tau}<1$ and

$$
\Phi_{\phi_{\tau}}^{B}\left(\phi_{\tau}, \phi_{\pi}, \delta\right)=\frac{(1-\beta) \delta \beta^{2} \phi_{\pi}^{2}}{\left(-1+\phi_{\tau}-\phi_{\tau} \beta+\beta \phi_{\pi}\right)^{2}}>0 .
$$

Solving for $\delta^{T B}$ from

$$
\Phi^{B}\left(1, \phi_{\pi}, \delta^{T B}\right)=\frac{\left(\beta^{2} \phi_{\pi}^{3}-\beta^{2} \phi_{\pi}^{3} \delta^{T B}-\beta^{2} \phi_{\pi}^{2}-2 \beta \phi_{\pi}^{2}+\beta \phi_{\pi}^{2} \delta^{T B}+2 \beta \phi_{\pi}+2 \phi_{\pi}-2\right)}{\left(1-\beta \phi_{\pi}\right)\left(1-\phi_{\pi}\right)}=0
$$

provides

$$
\delta^{T B}=\frac{\left(\left(1-\beta \phi_{\pi}\right)+\phi_{\pi} \beta^{2}+\left(1-\beta \phi_{\pi}\right)-\phi_{\pi} \beta^{2}\left(1-\phi_{\pi}\right)\right)\left(1-\phi_{\pi}\right)}{\beta \phi_{\pi}^{2}\left(1-\beta \phi_{\pi}\right)}>\delta^{T A} .
$$

Moreover, for $\phi_{\tau}>(1+\beta) /(1-\beta)$

$$
\operatorname{tr}(B)=\Phi_{\delta}^{B}\left(\phi_{\tau}, \phi_{\pi}, \delta\right)<0, \quad \text { and } \quad \Phi^{B}\left(\phi_{\tau}, \phi_{\pi}, 0\right)=-\left(\beta^{2} \phi_{\pi}^{2}-2 \beta \phi_{\pi}+2\right) /\left(1-\beta \phi_{\pi}\right)<0
$$

Finally, the determinant is equal to one for all parameter values.

\section{G Proof of Proposition 6}

Ricardian regime. Given the results in the Propositions above, it is sufficient to evaluate the matrix $A$. Evaluating the expression (38) at $\delta=1$ gives

$$
1+(\beta-1) \phi_{\pi}<0
$$


which coincides with the stability condition in the case where the agents have no knowledge about the policy rule. Thus, communication is always stability enhancing. The case of $\delta=0$ is trivial.

Non-Ricardian regime. Let $\delta=1$. then

$$
\begin{aligned}
\Phi^{A}\left(\phi_{\tau}, \phi_{\pi}, 1\right) & =\frac{\left(\beta^{2} \phi_{\pi} \phi_{\tau}+2 \beta \phi_{\pi}-\beta \phi_{\pi} \phi_{\tau}-\phi_{\tau} \beta+2 \phi_{\tau}-2\right)}{1-(1-\beta) \phi_{\tau}-\beta \phi_{\pi}} \\
& =-\left[1+\frac{1-\left[1-\beta \phi_{\pi}(1-\beta)\right] \phi_{\tau}-\beta \phi_{\pi}}{1-(1-\beta) \phi_{\tau}-\beta \phi_{\pi}}\right]
\end{aligned}
$$

which is the trace obtained about for the case of no communication. The function $\Phi^{A}$ is defined in the proof ${ }^{35}$ of Proposition 4. Since $\Phi_{\delta}^{A}>0$ for $0<\phi_{\tau}<1$ we have that $\Phi^{A}<\Phi^{A}\left(\phi_{\tau}, \phi_{\pi}, 1\right)$ for $\delta<1$. Hence, communication improves stability. Finally,

$$
\Phi^{A}\left(1, \phi_{\pi}, 0\right)=-\frac{\beta^{2} \phi_{\pi}-\beta^{2} \phi_{\pi}^{2}+(1-\beta)\left(1-\phi_{\pi}\right)}{(1-\beta)\left(1-\phi_{\pi}\right)}<0
$$

thus restoring the Leeper conditions. The case where $\phi_{\tau}>(1+\beta) /(1-\beta)$ is trivial from the proof of proposition 4 .

\section{H Proof of Proposition 7:}

As in proposition 4 , we can show that

$$
\lim _{\alpha \rightarrow 0} \alpha \cdot \operatorname{tr}(A)=\frac{\sigma+\delta \phi_{\pi} \beta-\phi_{\pi} \sigma}{(1-\beta) \sigma}
$$

which gives the desired result. The expressions below are calculated using the file fiscal_analytical_trsp.m.

\footnotetext{
${ }^{35}$ The expressions below are generated by the same Matlab file used for the poof of Proposition 7.
} 


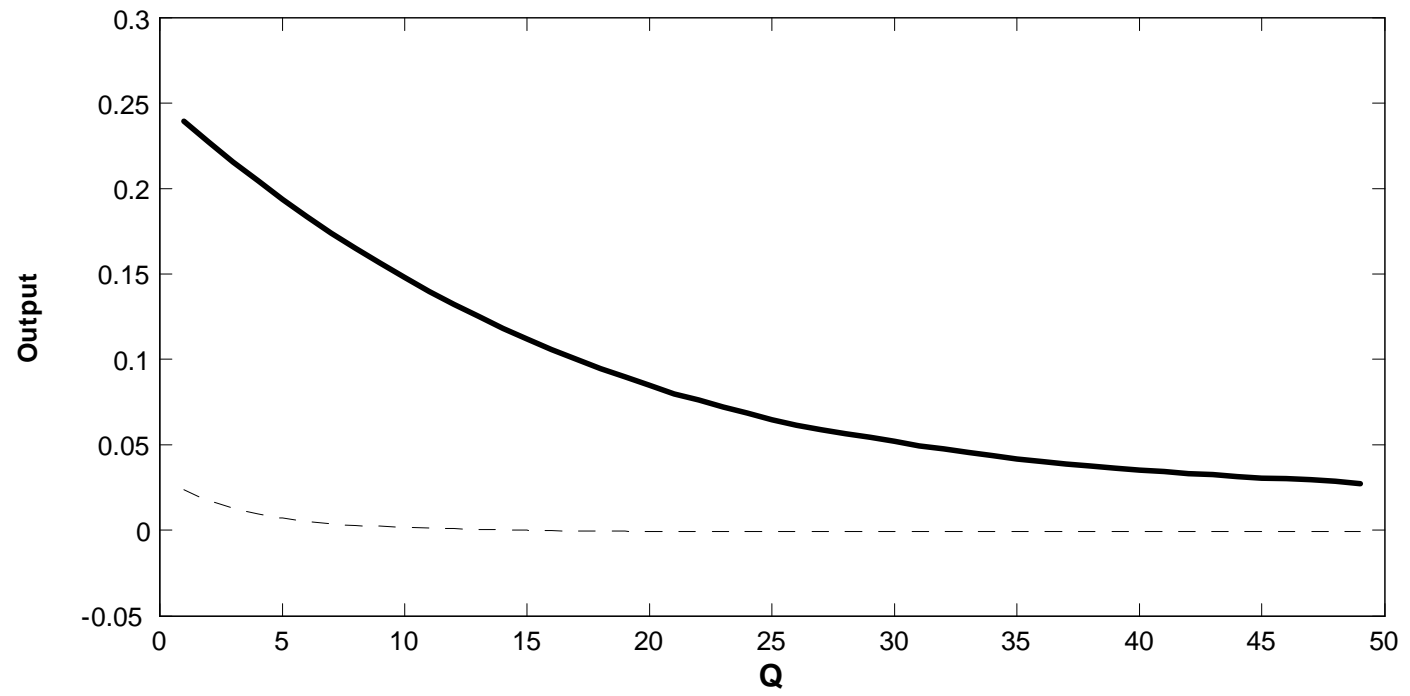

Figure 1: The solid line describes the output response under uncertainty about the monetary policy regime. The dotted lines shows the output response when agents know the monetary polic rule.

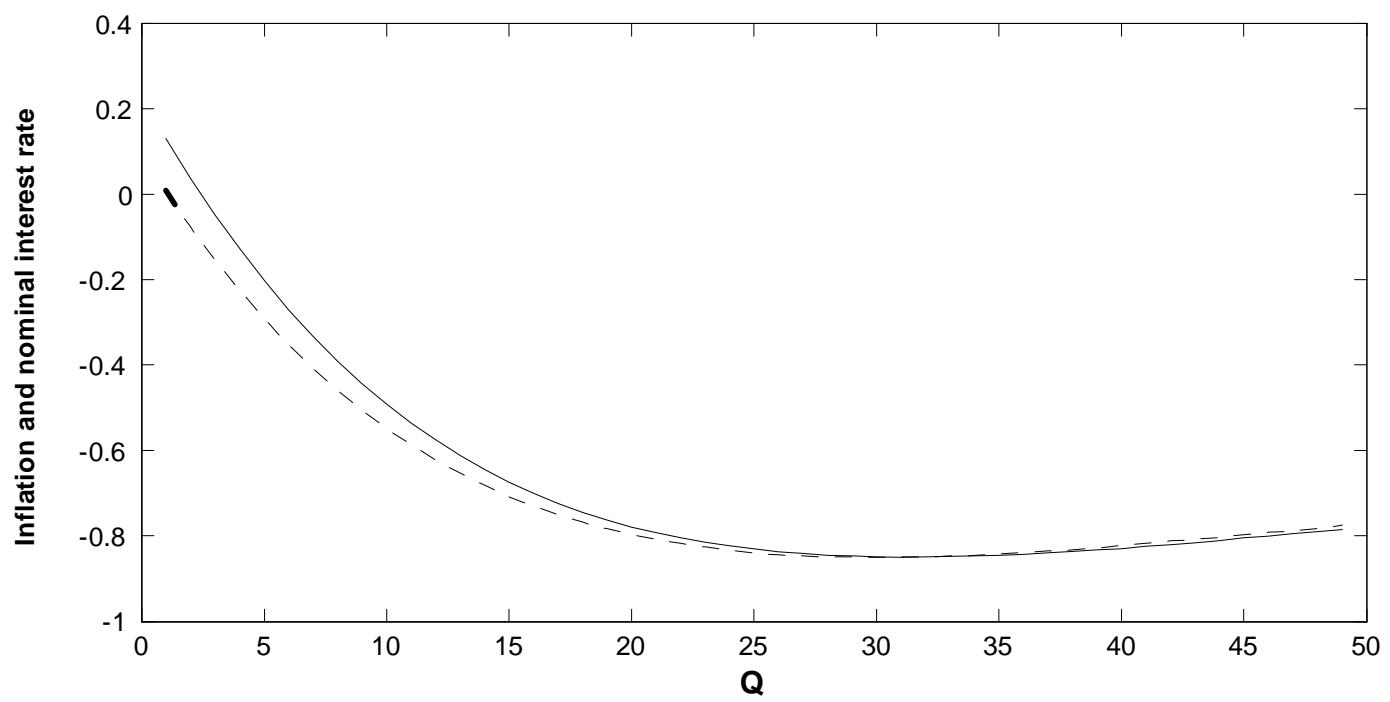

Figure 2: The figure shows the response of inflation (solid line) and nominal interest rate (dotted line) in the economy where agents face uncertainty about the monetary policy regime. Notice that the nominal interest rate is below current inflation for 25 quarters. 


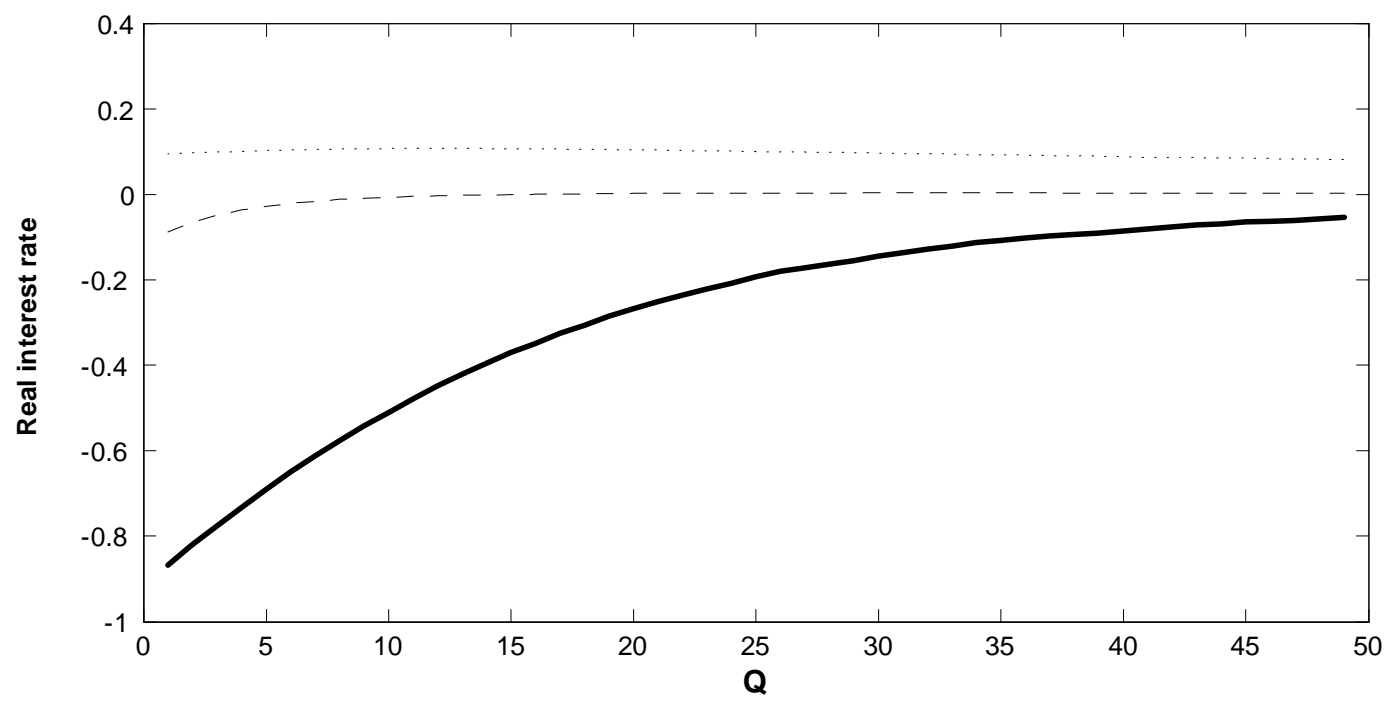

Figure 3: The figure shown the response of real rates. The solid line show the response of $\rho_{t}$, the long-term interest rate, under uncertainty about the monetary policy regime. The dashed line shows the response of $\rho_{t}$ when agents know the monetary policy rule. Finally, the dotted line show the short-term real interest rate $\left(i_{t}-\hat{E}_{t} \pi_{t+1}\right)$ under uncertainty about the monetary policy regime.

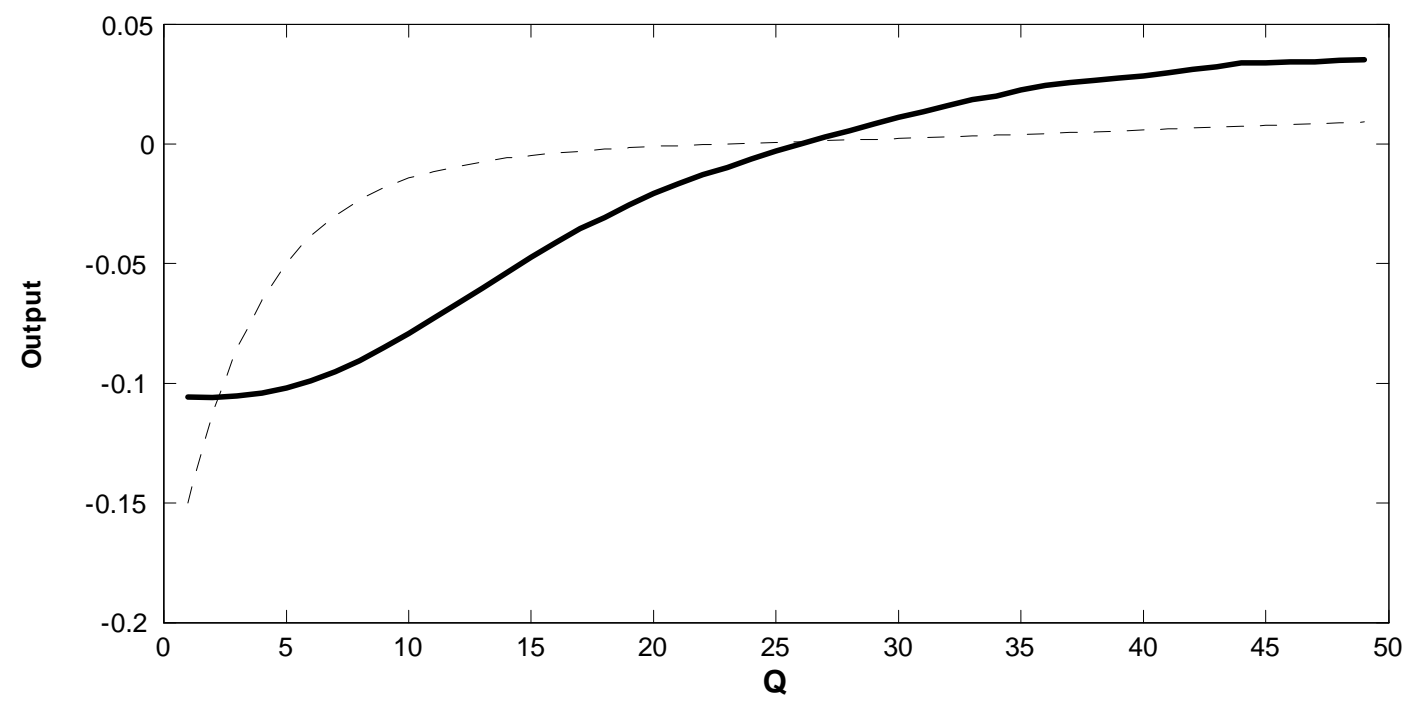

Figure 4: The figure shows the impulse response of output in the high debt economy (solid line) and in the zero debt economy (dashed line). 


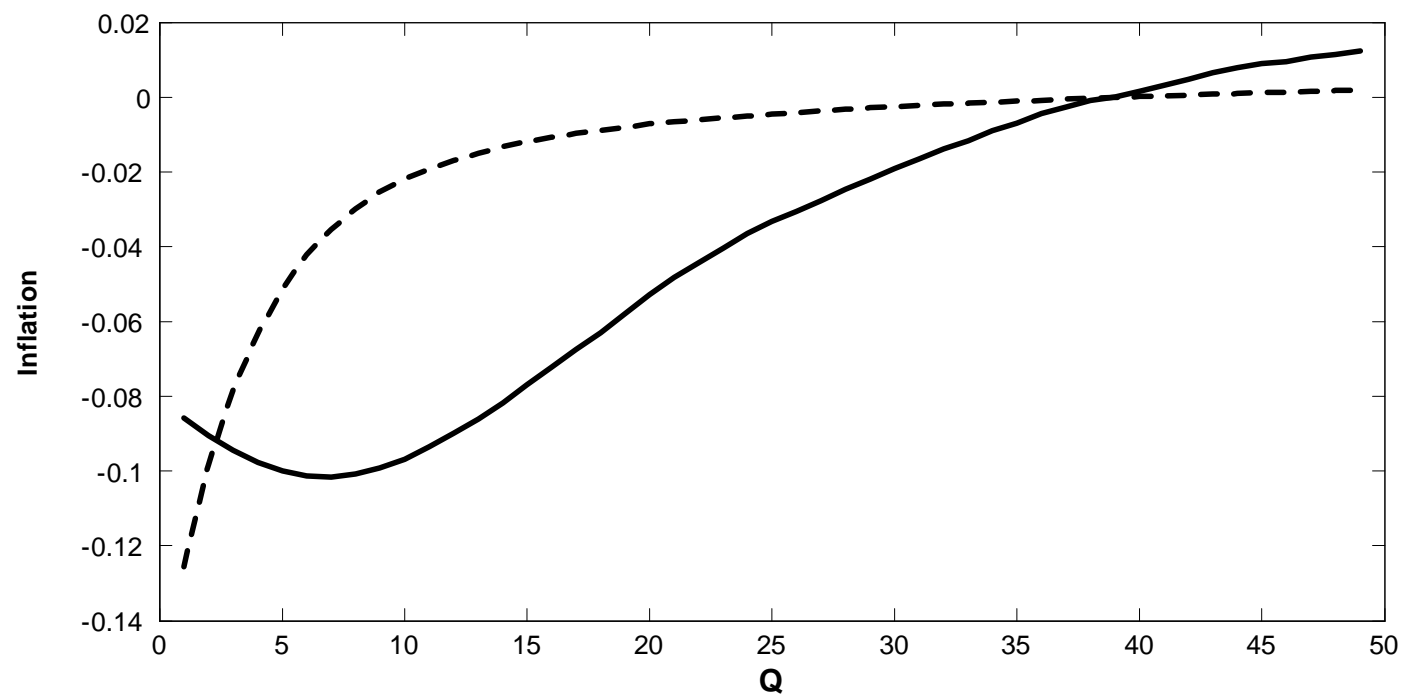

Figure 5: The figure shows the impulse response of inflation in the high debt economy (solid line) and in the zero debt economy (dashed line).

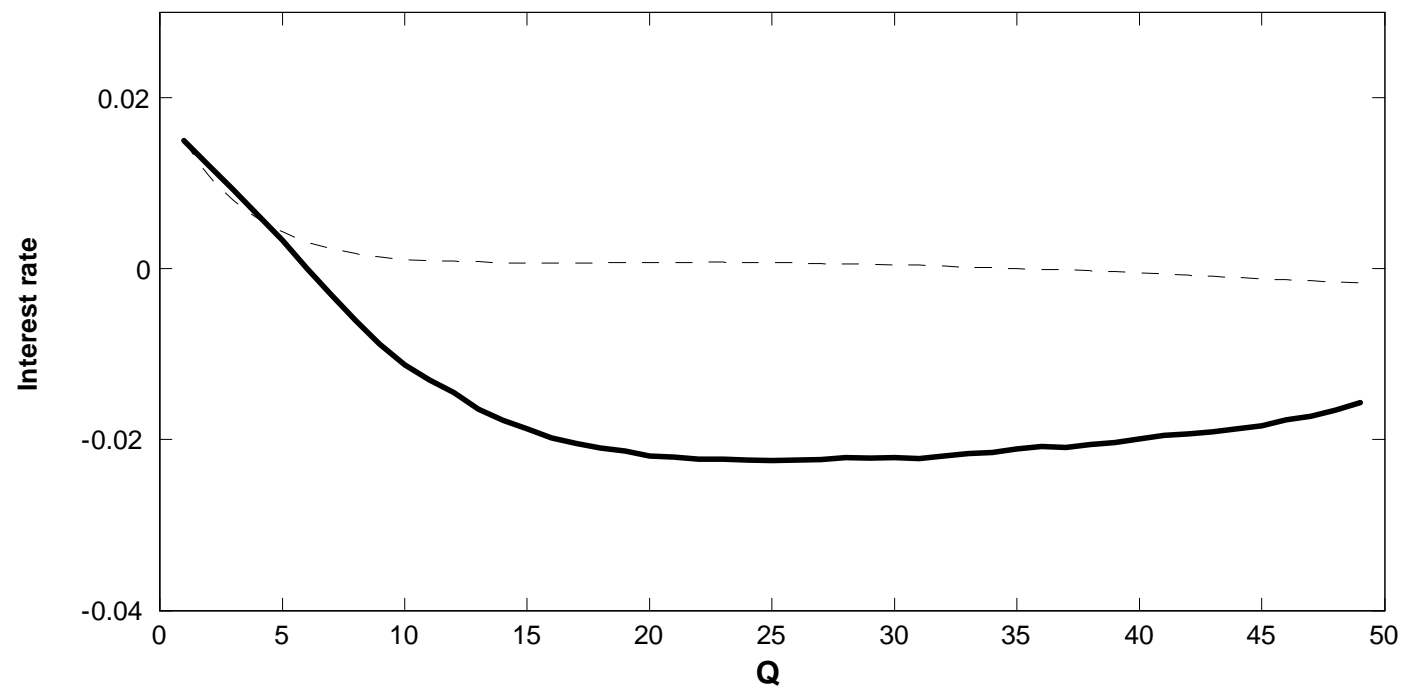

Figure 6: The figure shows the impulse response of the nominal interest rate in the high debt economy (solid line) and in the zero debt economy (dashed line). 


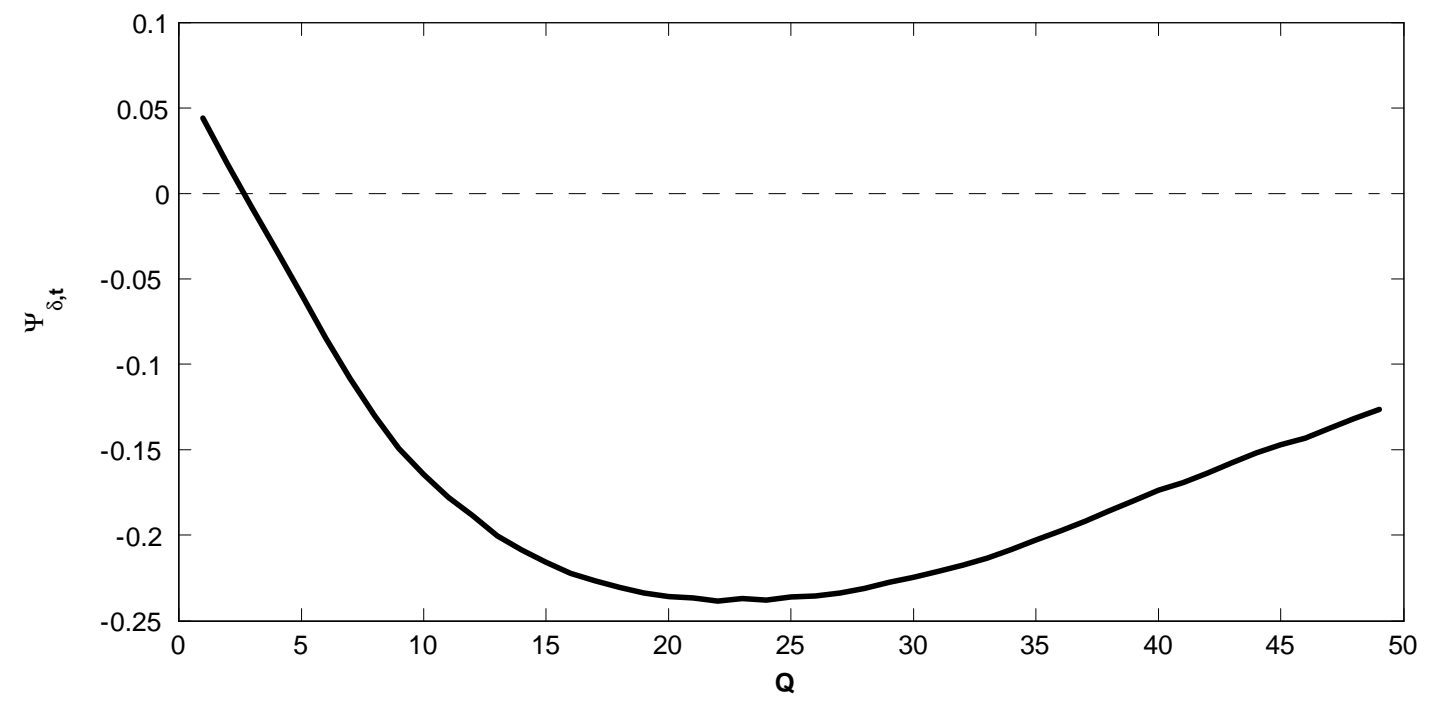

Figure 7: The figure shows the impulse response of the nonricardian term $\Psi_{\delta, t}$ in the high debt economy (solid line) and in the zero debt economy (dashed line).

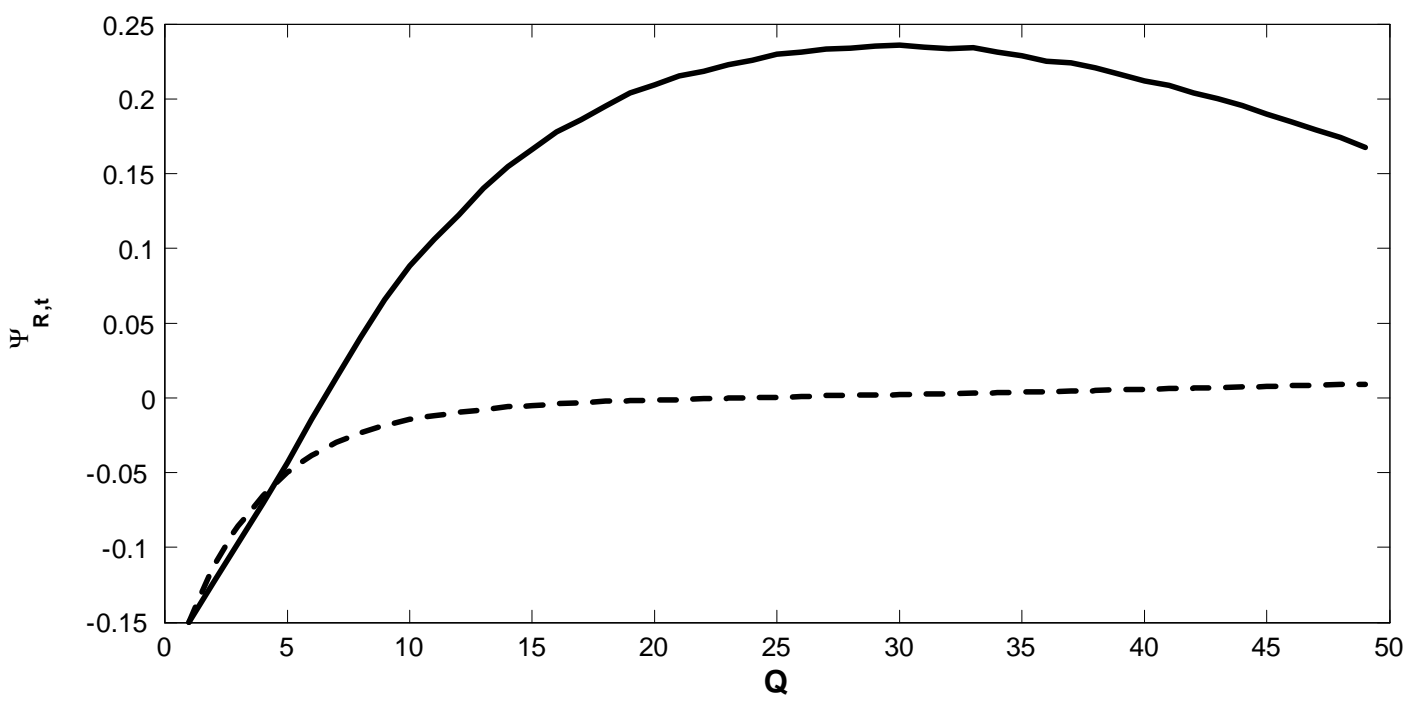

Figure 8: The figure shows the impulse response of the ricardian term $\Psi_{R, t}$ in the high debt economy (solid line) and in the zero debt economy (dashed line). 


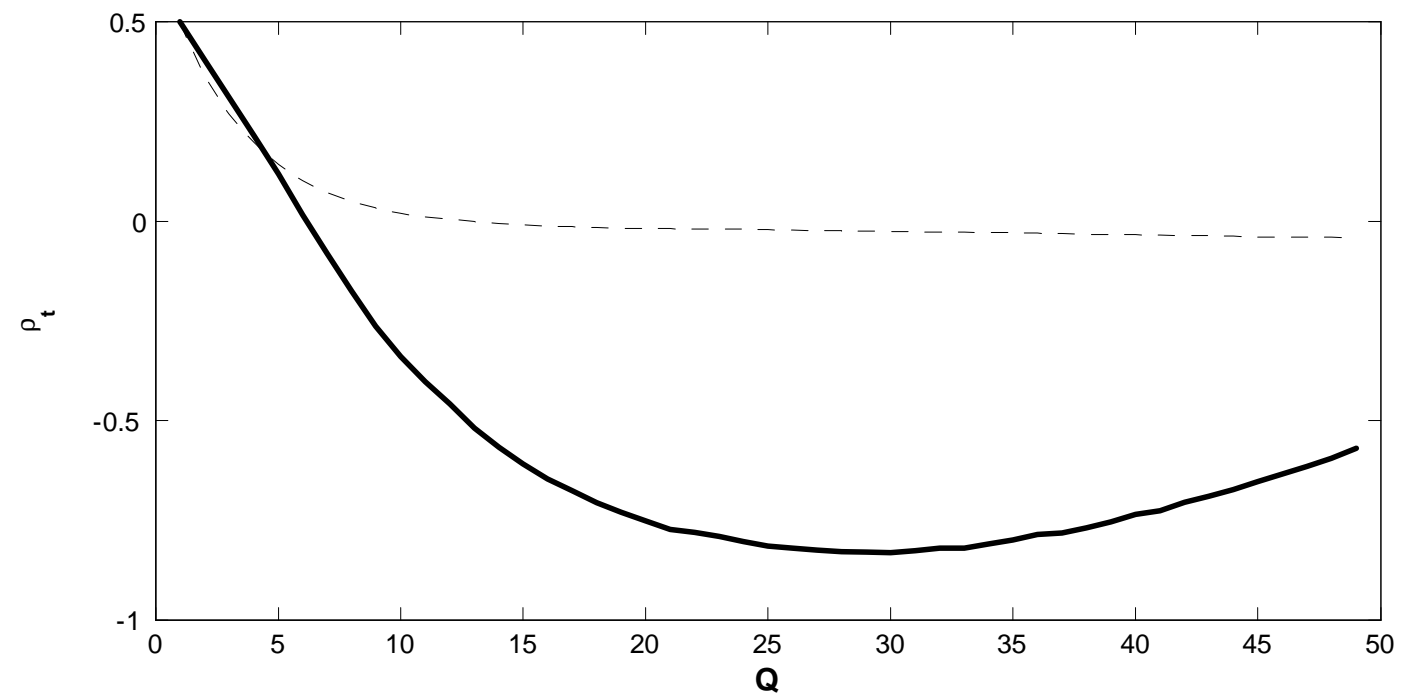

Figure 9: The figure shows the impulse response of the expected long-term interest rate $\rho_{t}$ in the high debt economy (solid line) and in the zero debt economy (dashed line).

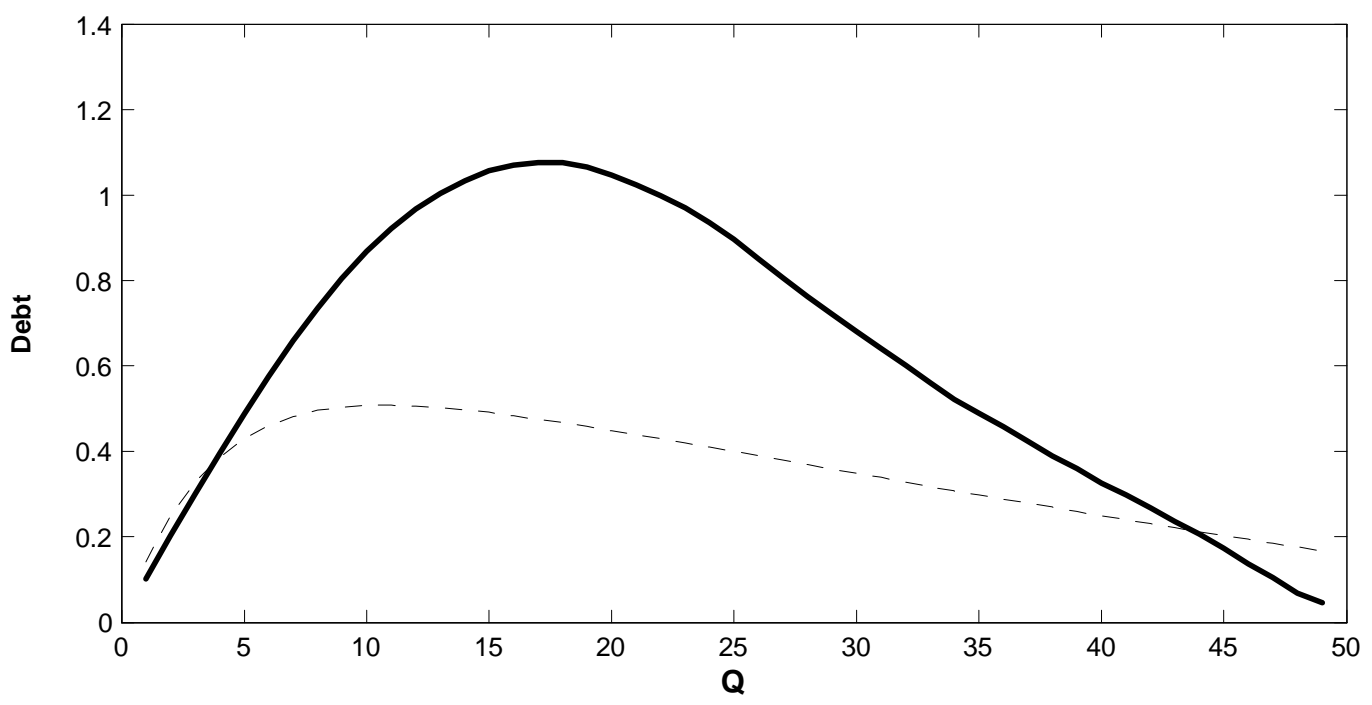

Figure 10: The figure shows the impulse response of real debt in the high debt economy (solid line) and in the zero debt economy (dashed line). 